\title{
Life Course Health Development Outcomes After Prematurity: Developing a Community, Clinical, and Translational Research Agenda to Optimize Health, Behavior, and Functioning
}

\author{
Michael E. Msall, Sarah A. Sobotka, \\ Amelia Dmowska, Dennis Hogan, \\ and Mary Sullivan
}

Definitions Late preterm infants (LPIs) $34^{0 / 7}$ $36^{6 / 7}$ week infants; moderate preterm infants (MPI) $32^{0 / 7}-33^{6 / 7}$ week infants; very preterm infants (VPI) 280/7-316/7 weeks; extreme preterm infants (EPI) $<28^{0 / 7}$ weeks; cerebral palsy (CP); normal birth weight (NBW) $\geq 2500 \mathrm{~g}$; low birth weight (LBW) 1500-2499 g; very low birth weight (VLBW) 1000-1499 g; extremely low birth weight (ELBW) $<1000 \mathrm{~g}$; $I Q=$ intelligence quotient; $I D=$ intellectual disability

\section{Introduction}

National vital statistics from 2013 estimate that the rate of preterm birth ( $<37$ weeks of gestation) involves approximately 1 in 10 infants in the United States each year (Hamilton et al. 2015). An estimated 68 per 1000 US live births, over 270,000 annually, are born at late preterm gestation (34-36 weeks). Currently, 28 per 1000 US live births, more than 100,000 infants annually,
M.E. Msall, MD ( $\bowtie)$

Developmental and Behavioral Pediatrics University of Chicago, Comer and LaRabida Children's

Hospitals, Chicago, IL, USA

JP Kennedy Research Center on Intellectual and Developmental Disabilities, University of Chicago Comer Children's Hospital, Section of

Developmental and Behavioral Pediatrics, 950 East 61St Street, SSC Room 207,

Chicago, IL 60637, USA

e-mail:mmsall@peds.bsd.uchicago.edu
S.A. Sobotka, MD, MS • A. Dmowska, BA Section of Developmental and Behavioral Pediatrics, University of Chicago Comer Children's Hospitals, Chicago, IL, USA

D. Hogan, $\mathrm{PhD}$ Sociology and Demography, Population Research and Training Center, Brown University,

Providence, RI, USA

M. Sullivan, $\mathrm{PhD}, \mathrm{RN}$

University of Rhode Island, College of Nursing, Women and Infants Hospital, Providence, RI, USA 
are born $<34$ weeks of gestation, and 56,000 are born at very low birth weight status $(<1500 \mathrm{~g})$. These infants have high risks for long-term neurodevelopmental disabilities such as intellectual disability (ID), blindness, sensorineural hearing loss, and cerebral palsy (CP). There are several biomedical causes for these high rates of preterm birth, such as the role of assisted reproductive technologies increasing the rate of multiple births (twins, triplets, or quadruplets) and maternal age. Teenage pregnancy, also a risk factor for prematurity, has instead been decreasing over the past decade (Hamilton et al. 2015; The March of Dimes Data Book for Policy Makers 2012). However, it is very critical to remember that both very preterm infants (VPI) and extreme preterm infants (EPI) are heterogeneous, and our understanding of causal pathways that lead to successful interventions is at an early scientific stage (Rubens et al. 2014). For example, the same factors that create the biological risk in the mothers for prematurity may be the same factors that influence the inflammatory, hormonal, and neurochemical regulators that influence the mothers' caregiving capacity once their premature infant is born. Therefore, ascribing causality to biomedical, behavioral, or neuro-regulatory factors is difficult and does not allow for the complex systems understanding required to advance life courseoriented prevention and intervention strategies. In addition, despite increased access to prenatal care, there still remain limitations on our ability to prevent all moderate and late preterm birth (Requejo et al. 2013).

Estimates of the economic impact of prematurity typically factor in acute care medical costs, early childhood intervention expenditures, longterm special education, special health care, and disability costs. A report released by the Institute of Medicine in 2007 estimated that the economic burden associated with preterm birth was at least $\$ 26.2$ billion in 2005 , equivalent to $\$ 51,600$ per infant born preterm. These estimates included $\$ 16.9$ billion in medical care costs, $\$ 1.9$ billion in maternal delivery costs, $\$ 611$ million for early intervention services, $\$ 1.1$ billion for special education services, and $\$ 5.7$ billion in lost household and labor market productivity (Preterm
Birth: Causes, Consequences, and Prevention 2007). Importantly, each premature/LBW baby costs employers an average of $\$ 54,149$ in payments for newborn medical care during the first year of life, about twelve times that of an uncomplicated newborn (Preterm Birth: Causes, Consequences, and Prevention 2007). In addition to medical care, children born preterm are more likely to experience learning and behavior disabilities later in life, often resulting in poor test scores, grade repetition, and increased utilization of special education services. The Institute of Medicine estimates the costs of special education at \$2200 per year per child (Preterm Birth: Causes, Consequences, and Prevention 2007), though for children with major neurodevelopmental disabilities, the special cost per child can exceed \$50,000 per academic year.

High-quality early childhood intervention programs, however, may minimize the later need for special education and drastically reduce these additional costs (Aron and Loprest 2012). Model programs like the Infant Health Development Program (IHDP) are successful in improving educational, behavioral, and life course outcomes for preterm infants experiencing poverty, thereby decreasing children's need for special education (Aron and Loprest 2012). Economic modeling estimates the impact of comprehensive early intervention services on long-term special education costs as having a direct savings of $\$ 2.60$ for every dollar invested in early intervention, early childcare services, and Early Head Start (Dmowska et al. 2016). When considering costs incurred from school dropouts, reentry to school, and additional weight on mental health-care services and the criminal justice system, the savings would likely double (Dmowska et al. 2016). Increased access to comprehensive familycentered early intervention services, therefore, may substantially reduce special education costs for children born preterm as well as long-term behavioral and social health costs.

There have been dramatic improvements in long-term survival for infants born premature and low birth weight, but developmental outcomes are far from optimized. Survival has increased dramatically with the regionalization of neonatal 
intensive care and the application of obstetrical and neonatal biomedical interventions for optimizing growth, lung maturity, cardiopulmonary functioning, and infection control. Overall, these efforts resulted in decreased rates of major neurodevelopmental disabilities in survivors in the 1980 s and 1990 s from $25-40 \%$ to $15-25 \%$. For those born with extreme prematurity $(<28$ weeks of gestation) and extremely low birth weight status $(<1000 \mathrm{~g})$, survival has increased dramatically from $<50 \%$ to $>80 \%$. However, there remain high rates of cognitive impairment and intellectual disability (ID), with over $50 \%$ of survivors requiring special education services.

Growing inequality in the United States hits families with young children very hard. Close to $50 \%$ of children younger than 5 are growing up in households living below $200 \%$ of the poverty level. Research shows that families with this level of income do not have the economic, social, educational, and community assets they need to support optimal health development (Crouter and Booth 2014). So many of the $8 \%$ premature babies, who start off life with higher levels of inherent vulnerabilities, are increasingly facing a family, social, and community landscape that cannot support their optimal development.

In addition, there is increased recognition that both moderate and late preterm births (3236 weeks of gestation), which account for over $8 \%$ of live births or approximately 325,000 children yearly, have increased risk for long-term health, developmental, and behavioral challenges (Table 1). In spite of these biomedical advances, environmental and social conditions that can deleteriously affect the health and well-being of these already vulnerable children have not only improved in the United States; there are some indications that they have in fact worsened.
Additionally, there are major gaps in accessing comprehensive family supports and quality health, early childhood, and educational and community experiences for recent cohorts of children at the highest biomedical and social risks.

The purpose of this paper is to apply a life course health development perspective in order to identify factors that promote more optimal health and developmental trajectories and the mechanisms that underlie resilience for children with prematurity from a life course health development perspective. We will describe some research findings about the role of social and environmental factors among VPI and EPI survivors in aggravating or moderating neonatal risks for suboptimal developmental and behavioral outcomes. We will also discuss available evidence from longitudinal studies of preterm children at psychosocial disadvantage and what lessons can be learned from the bidirectional impacts of prematurity and poverty. Longitudinal studies will be evaluated for health, disability, and community outcome trajectories for children with prematurity across preschool, middle childhood, adolescent, and young adult epochs. Our review will highlight important opportunities on a community level for systematically optimizing population-based prevention strategies for individuals with the double jeopardy of prematurity and social adversity and the long-term impact of failing to optimize these outcomes.

\subsection{Approach}

Two frameworks will inform our analysis. The first framework will be the International Classification of Functioning, Disability, and Health (ICF) model (World Health Organization

Table 1 Life course impact of prematurity

\begin{tabular}{l|l|l|l|l}
\hline Weeks gestation & $\begin{array}{l}\text { Children special } \\
\text { health-care needs }\end{array}$ & $\begin{array}{l}\text { Major neurodevelopmental } \\
\text { disability }\end{array}$ & Educational supports & Behavioral disorders \\
\hline$<28$ & $50 \%$ & $20 \%$ & $50 \%$ & $20 \%$ \\
\hline $28-31$ & $40 \%$ & $15 \%$ & $40 \%$ & $15 \%$ \\
\hline $32-36$ & $30 \%$ & $10 \%$ & $25 \%$ & $10 \%$ \\
\hline
\end{tabular}

Morse et al. (2009), Allen et al. (2011), Stephens and Vohr (2009), B. Vohr (2013), Saigal and Doyle (2008) 
2007), which we will use to comprehensively describe the diverse outcomes occurring in preterm survivors. This framework goes beyond dichotomous classification of impairments (e.g., cerebral palsy, yes or no; intellectual disability, yes or no) and instead describes a spectrum of functioning at body structure and body function levels. For example, activities in whole-person tasks include running, reading, and dancing and participation in children's roles with peers including being on a team; participating in church, temple, or mosque; or meeting friends for a movie.

The second framework will be the life course health development (LCHD) model, which holds that the trajectories of children are influenced by the dynamic interaction of multiple risk, protective, and promoting factors, especially during sensitive periods of health development. From the standpoint of fetal development, due to critical human brain development in the second and third trimesters, a focus on premature infants must consider complex maternal, placental, and fetal dynamic interactions. Likewise, infant, toddler, and childhood periods of development are indelibly influenced by multilevel, multidirectional, transactional, and long-lasting interactions and critically emphasize the importance of timing. Using a LCHD framework to analyze the origins and impact of prematurity and the opportunities to optimize health development outcomes suggest the following considerations:

- Children who are born prematurely are assumed to be more developmentally vulnerable and are potentially more sensitive to a wide range and nested array of dynamic interacting influences.

- Because the alterations in evolutionarily influenced and developmentally determined adaptive mechanisms are well documented, lags in developmental processes, as well as catch-up and feed-forward processes that are specific to premature infants, may influence the nature and dynamic of their health and developmental trajectories.

- Understanding how the caregiving environment of premature infants interacts with emerging developmental capacities and how different types of exposures, levels of support, and adversity influence these emergent developmental trajectories is important if specific and targeted interventions are to be designed to modify developmental pathways based on specific risk profiles to shift the health and developmental curves for the entire population of premature infants.

- In order to implement a broader approach to improve the health and developmental outcomes of diverse preterm populations, it is important to determine what is known about the special development vulnerabilities of premature infants, how that vulnerability manifests (timing, context, specific risks), and whether the mechanisms involved are phase or period specific, modifiable, or one of cumulative risk.

\section{$2 \quad$ Framing Our Inquiry and Agenda}

On a population level, it is important to acknowledge the diversity of both the underlying causes and life course effects of prematurity and the gaps in proactive and comprehensive medical, developmental, and behavioral supports. This is occurring within the context of recognizing that current community systems are under-resourced to systematically audit barriers and facilitators to home visiting, medical homes, early interventions, parenting supports, and coordinated services for children with special health-care needs (CSHCN). In particular, we must go from a crisis-oriented response system for the few with the severest impairments to an optimization system for all at risk for less than optimal health development.

To address these systemic needs, the following themes will be highlighted that require increased research and policy efforts:

- We must better understand the role of and need to engage mothers and other caregivers in developmentally optimizing interactions from the neonatal period through school entry. This includes how they gain and utilize their knowledge about their child's health and development, as well as how to optimally serve as their 
child's first teacher and advocate. This requires understanding ways that early parent involvement and developmental activities can be part of everyday childcare tasks.

- We must explore how social environments are best tailored to maximally support positive growth, child regulatory behaviors, and developmental competencies. This includes how all children can access comprehensive preschool services and how health, developmental, and behavioral competencies are measured, monitored, and accounted for from birth to kindergarten entry. In keeping with a two-generation model of optimizing health development, close attention to caregiver physical and behavioral health and supports that help vulnerable children access quality childcare and early child education have the potential to ensure that children's social-emotional, communicative, and cognitive competencies are supported so that children enter kindergarten healthy and ready to learn.

- We must clarify the roles that preconception maternal, physical, and behavioral health play on maternal and child vulnerabilities and on epigenetic programming. This includes a better understanding of how maternal mental health stressors (depression, anxiety, isolation, and violence) increase vulnerability of children when they do not receive quality early childhood social, learning, and behavioral supports.

- We must determine the optimum and appropriate role and function of community outreach strategies that promote parental physical and behavioral health, child development, and social competencies.

- We should pursue evidence-based strategies to promote resiliency and positive adult health trajectories which include independent living, employment, and family formation while minimizing physical risk factors that increase early-onset adult chronic diseases (e.g., cardiac, pulmonary, mental illness, substance abuse) (Figs. 1 and 2).

Our cases illustrate how the interaction of positive home, preschool, and educational supports can increase thriving and reduce adverse longterm adult health conditions.

\section{$3 \quad$ Risk Factors for Poor Birth Outcomes}

\subsection{Social Risks}

An important determinant of preterm birth is social risk. Social risk factors include suboptimal home and community environments. Poverty, domestic violence, drug addiction, crime, hunger, and poor-quality housing are some of the features of social risks (Holzmann and Jørgensen 2001). Mothers who live in adverse environments often experience multiple stressors and are prone to nutritional deficiency, suboptimal prenatal care, single parenthood, and frequent tobacco and alcohol use compared to mothers from nonpoor backgrounds (Jiang 2015). Several studies have also shown that rates of marijuana, cocaine, tobacco, and alcohol use are higher for women who are unmarried, unemployed, and have less than a college education, indicating that substance abuse and poverty are closely related (Huston 1991). It has been suggested that the prevalence of substance abuse, illicit drug use, and smoking among women from impoverished or low SES background is largely due to the sense of helplessness, low self-esteem, difficulties coping with stress, and pressure from coping with difficult financial situations in everyday living (Huston 1991; Weitzman et al. 2002).

When mothers receive late prenatal care (or not at all), the opportunity to identify and intervene on maternal reproductive complications or health problems that jeopardize fetal growth is limited. Also, late or no prenatal care decreases the chances of maternal access to educational and support services (such as counseling, community health, and education services) (The March of Dimes Data Book for Policy Makers 2012).

\subsection{Race and Social Disadvantage}

Race in the United States is closely related to SES; thus, it is not surprising to see racial discrepancies in preterm births (Table 2). AfricanAmerican infants are more than 1.5 times likely than whites to be born preterm and 2.5 times likely to be very premature than their white peers 


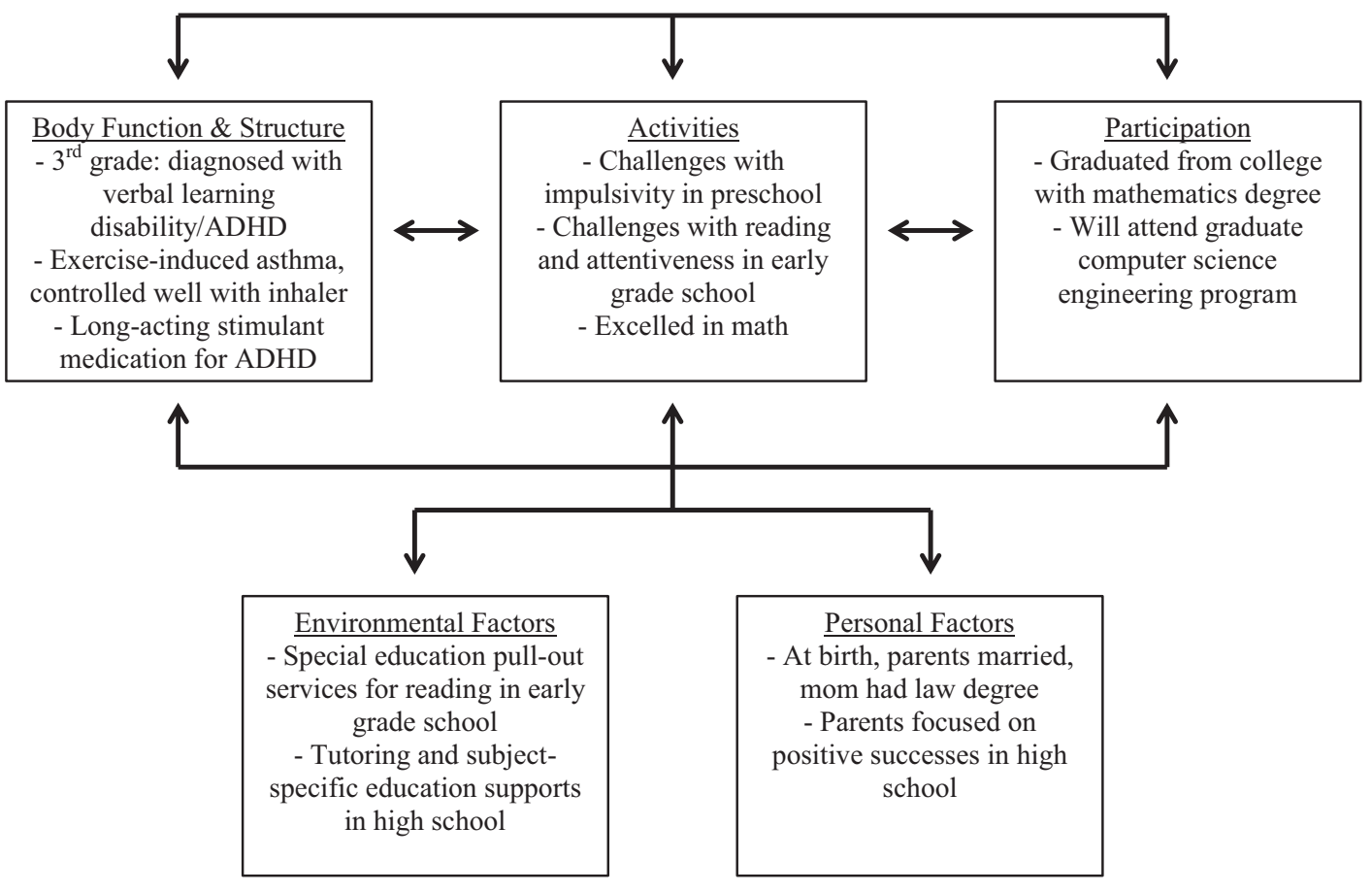

Fig. 1 Case 1. James was born late preterm at 34 weeks of gestation due to preeclampsia. His parents were married and mother completed law school. She had some challenges with impulsivity in preschool, and reported significant job-related stressors during pregnancy. The immediate newborn period was complicated by immature lungs leading to respiratory distress syndrome; however, ultimately James was discharged at 38 weeks of gestational age without a need for oxygen in the home. He was enrolled in full-day daycare and preschool since the age of 2 years. James was found to have some challenges with impulsivity in preschool, which his parents addressed with occupational and behavioral therapies. He entered kindergarten without an Individualized Education

(The March of Dimes Data Book for Policy Makers 2012). These data on preterm birth rates correlate with disparities in wealth distribution, with African-American families experiencing the lowest 3-year average median income (20032005) among US racial groups (Income, Poverty, and Health Insurance Coverage in the United States: 2005-2006). These data on higher rates of prematurity in women experiencing social disadvantage from poverty and minority status also hold across both developing and developed countries. The role of maternal health, educational, behavioral, and social competencies during her own childhood and how they impact on
Program and in early grade school was found to struggle with reading and inattentiveness. He received a formal diagnosis of verbal learning disability and ADHD in third grade. James received special education pull-out services for reading and language arts and was starting on a longacting stimulant medication for ADHD with the guidance of a Developmental and Behavioral Pediatrician. James received tutoring and subject-specific special education supports throughout high school. His parents focused on his positive successes, such as his strong performance in math. James went to college and pursued a math and engineering program. His adult health is complicated by exercise-induced asthma, well-controlled on an inhaler

her child's health and development require systematically measuring both maternal and child allostatic load. These data can help understand what factors promote positive adaptations.

\section{$4 \quad$ Prematurity and Developmental Outcomes}

Prematurely born infants have long-term vulnerabilities on multiple outcomes, including physical and developmental health, behavioral and adaptive well-being, as well as social functioning. Over the past decade, much has been learned 


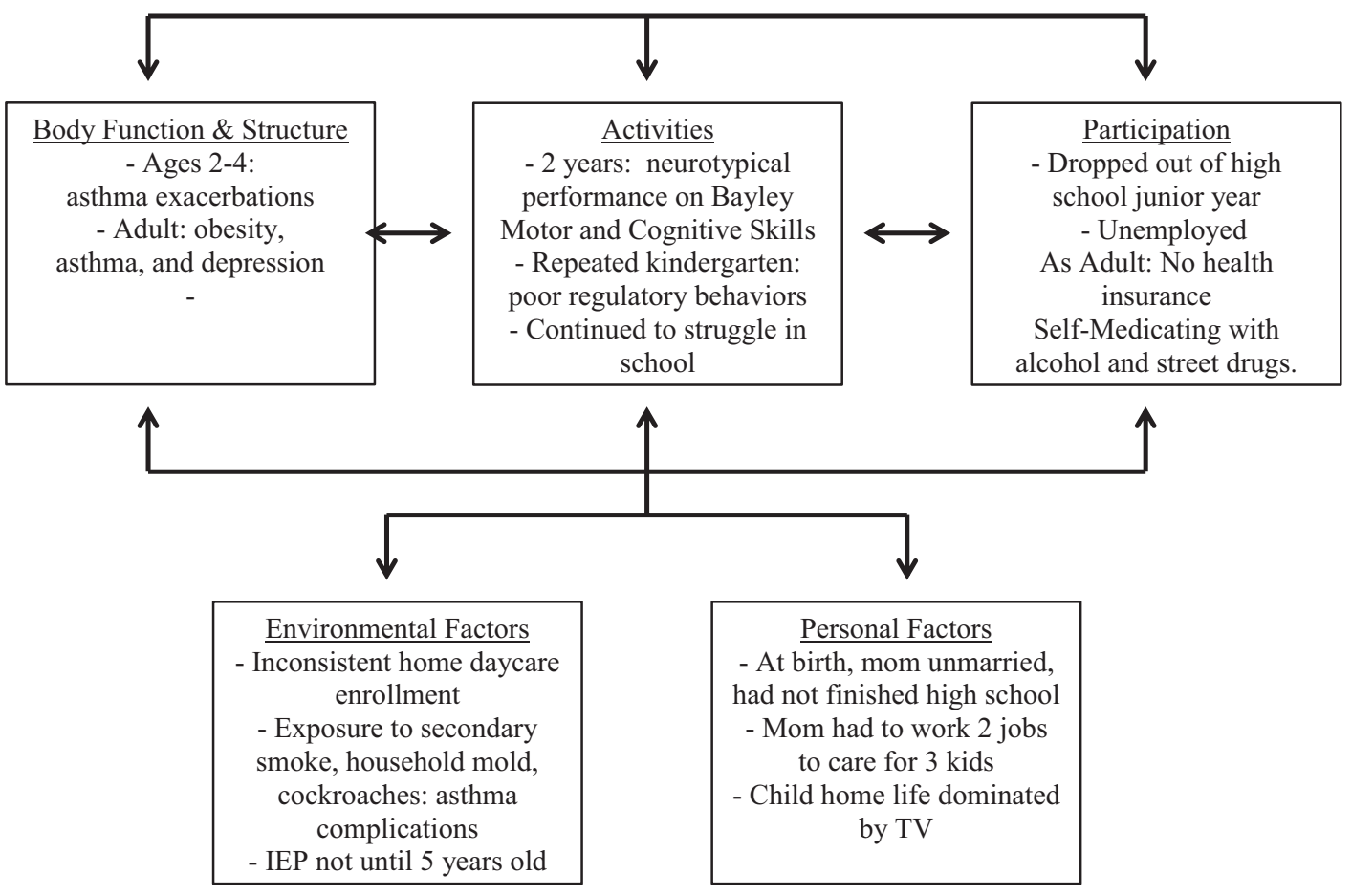

Fig. 2 Case 2. Michael was born at 28 weeks due to preeclampsia and preterm labor. His mother was unmarried and did not finish high school. His NICU course was complicated by intubation for the first 4 weeks of life, but he did not experience additional medical complications and was able to be slowly transitioned to room air and oral feedings. At 2 years of age, he tested within age appropriate range on the Bayley Scales of Toddler Development. Between ages 2 and 4, he experienced asthma exacerbations complicated by environmental exposures to secondary tobacco smoke, household mold, and cockroach infestation and was hospitalized about 2-3 times a year. Until the age of 5 years, Michael was enrolled in inconsistent home daycare programs and did not receive early intervention services

in the management of preterm infants and the interventions required to stabilize their immature organ system functioning.

Table 2 Rate (\%) of preterm birth by maternal race and trimester of first prenatal visit

\begin{tabular}{l|l|l|l}
\hline $\begin{array}{l}\text { Trimester of } \\
\text { first prenatal } \\
\text { visit }\end{array}$ & $\begin{array}{l}\text { Non- } \\
\text { Hispanic } \\
\text { black }\end{array}$ & $\begin{array}{l}\text { Non- } \\
\text { Hispanic } \\
\text { white }\end{array}$ & Hispanic \\
\hline First & 14.7 & 8.3 & 9.7 \\
\hline Second & 17.6 & 10.2 & 10.0 \\
\hline Third & 16.0 & 10.0 & 10.0 \\
\hline None & 33.4 & 21.7 & 19.8 \\
\hline
\end{tabular}

Lang and Iams (2009) because he was considered less than $30 \%$ delayed and thereby was deemed not eligible for services. He enrolled in kindergarten at age 5 years. However, he had to repeat kindergarten due to poor regulatory behaviors, which interfered with learning. Throughout his early childhood education, he continued to struggle in school. His home life was largely dominated by television watching while his mom worked two jobs to help care for him and his two siblings. In school he was supported by an Individual Education Plan, but did not access pharmacotherapies for ADHD. He dropped out of high school in his junior year. His adult health is complicated by obesity, asthma, and depression. Because of unemployment, he does not have health insurance. His state has not expanded Medicaid access

\subsection{Cerebral Palsy and Neurosensory Impairment}

Table 3 highlights rates of CP and neurodevelopmental disabilities in early childhood among extremely preterm cohorts born into the medical era, which had both prenatal maternal corticosteroid and surfactant replacement interventions available. These studies demonstrate that, despite common misconceptions, the overwhelming majority of children who survive extreme prematurity do not experience CP. These data 
Table 3 Major neurodevelopmental disabilities at age 2 years among survivors of ELBW in the 1990s

\begin{tabular}{|c|c|c|c|c|c|}
\hline Study & Sample & $\% \mathrm{CP}$ & $\% \mathrm{DD}$ & $\% \mathrm{HI}$ & $\% \mathrm{VI}$ \\
\hline $\begin{array}{l}\text { Schmidt et al. } \\
(1996-1998)\end{array}$ & $\begin{array}{l}N=944 \\
500-999 \mathrm{~g}\end{array}$ & 12 & 27 & 2 & 2 \\
\hline $\begin{array}{l}\text { Mikkola et al. } \\
(1996-1998)\end{array}$ & $\begin{array}{l}N=206 \\
<1000 \mathrm{~g}\end{array}$ & 14 & 9 & 4 & 2.6 \\
\hline \multirow[t]{2}{*}{$\begin{array}{l}\text { Vohr et al. } \\
(1993-1998)\end{array}$} & $\begin{array}{l}N=2291 \\
22-26 \text { weeks }\end{array}$ & 19 & 30 & 2 & 2 \\
\hline & $\begin{array}{l}N=1494 \\
27-32 \text { weeks GA }\end{array}$ & 11.6 & 26 & 1 & 0.7 \\
\hline Wood et al. (1995) & $\begin{array}{l}N=283 \\
22-25 \text { weeks GA }\end{array}$ & 16 & 30 & 2 & 2 \\
\hline Doyle et al. (1997) & $\begin{array}{l}N=170 \\
500-999 \mathrm{~g}\end{array}$ & 11 & 22 & 1.8 & 2.4 \\
\hline $\begin{array}{l}\text { Mestan et al. } \\
(1998-2001)\end{array}$ & $\begin{array}{l}N=138 \\
27.4 \text { weeks GA }\end{array}$ & 9.5 & 27.3 & 0.8 & 1.5 \\
\hline $\begin{array}{l}\text { Shankaren et al. } \\
(1993-1999)\end{array}$ & $\begin{array}{l}N=246 ; \leq 750 \mathrm{~g} \\
\leq 24 \text { weeks; } \mathrm{APl} \leq 3\end{array}$ & 30 & 46 & 5 & 5 \\
\hline $\begin{array}{l}\text { Wilson-Costello et al. } \\
(1990-1998)\end{array}$ & $\begin{array}{l}N=417 \\
500-999 \mathrm{~g}\end{array}$ & 14 & 26 & 7 & 1 \\
\hline Fily et al. (1997) & $\begin{array}{l}N=545 \\
<33 \text { weeks GA }\end{array}$ & 9 & 4.7 & 0.8 & 0.2 \\
\hline
\end{tabular}

$D D$ developmental disability as defined as mental developmental index $<70$, $H I$ hearing impairment, $V I$ visual impairment

APl Apgar $1 \mathrm{~min}$

$G A$ gestational age

complement population registries, which dramatically highlight the increased rate of $\mathrm{CP}$ among preterm survivors with decreasing gestational age. In Sweden, EPI have rates of $\mathrm{CP}$ at 71 per 1000, VPI 40 per 1000, and LPI (32-36 weeks) 6.4 per 1000 , compared to term births at 1.1 per 1000 (Himmelmann and Uvebrant 2014).

Although there are many types of $\mathrm{CP}$ with varying degrees of difficulty with motor control and higher cortical function, the two most common types among preterm survivors are spastic diplegia and spastic hemiplegia. These CP syndromes affect the motor control of lower extremities (diplegia) or one side of the body (hemiplegia) and increase risks for communicative, perceptual, learning, and attention disorders (Allen et al. 2011). However, an examination of these broader outcomes for recent VPI and EPI cohorts at ages 5-8 years has not occurred in large United States regional or multicenter cohorts. Furthermore, functional measures of gross motor, manual ability, and communication activities offer more detailed descriptions of performance in everyday activities than topographical classifications of $\mathrm{CP}$.

Over the past decade, there has been an increased appreciation of a wider range of motor challenges that have been characterized as developmental coordination disorders. A developmental coordination disorder is defined by acquisition and execution of coordinated motor skills below what would be expected at a given chronologic age. Difficulties are manifested as clumsiness, slowness, and inaccuracy of performance of motor skills. These motor skill deficits persistently interfere with activities of daily living appropriate to the chronologic age (Diagnostic and Statistical Manual of Mental Disorders: DSM-5 2013). A systematic analysis of 14 studies of children $<33$ weeks of gestation and $<1501$ g demonstrated $41 \%$ had mild developmental coordination disorder (characterized by motor standard scores 1-2 standard deviations below the mean) and 19\% had moderate developmental coordination disorder $(\geq 2$ standard deviations below the mean) (Williams et al. 2010). 
The second column in Table 3 reviews rates of developmental disability. These studies demonstrated rates of cognitive disability ranging between 9 and 46\% among those EPI and 5\% when VPI and EPI were combined. It must be emphasized that their early cognitive disabilities do not fully capture long-term educational impact.

Among ELBW survivors, there are high rates of neurosensory impairments. Severe hearing impairment ranges from $1 \%$ to $7 \%$. This is also substantially higher than the 1 per 1000 rate in term infants. Another neurodevelopmental disability after prematurity is visual loss or blindness caused by retinopathy of prematurity (ROP). This disorder primarily affects premature infants weighing $1250 \mathrm{~g}$ or less and those born before 31 weeks of gestation. ROP in the current era of neonatology reaches its severest stages in those who are most immature and medically fragile. Severe visual impairment occurs in $1-2 \%$ of $<27$-week preemies, 20-40 times higher than in term infants. In a multicenter study on cryosurgery for ROP, increased severity of ROP was linked to motor, self-care, and communicative disability at kindergarten entry (Msall et al. 2000). Children with severe ROP, but with favorable visual acuity, had a motor disability rate of $5 \%$ compared to $43 \%$ of children with severe ROP and unfavorable visual acuity (eyesight worse than 6.4 cycles per degree on Teller Cards includes legal and total blindness). In this cohort, neonatal risk factors for severe disability involving multiple motor, self-care, and communicative domains included severe ROP, gestational age $<27$ weeks, birth weight $<750 \mathrm{~g}$, and poverty as reflected by the absence of private health insurance. A protective factor associated with a significant risk reduction for severe disability was African-American race. In middle childhood, children with severe ROP had substantial differences in cognitive and educational outcomes (Msall et al. 2004). Children with severe ROP and unfavorable visual status had a 3 in 5 chance of ID (57\%) and a 3 in 5 chance of needing special education services. Children with severe ROP and favorable visual skills had a 1 in 5 chance of ID (22\%) and a 1 in 4 chance of need- ing special education. More than 4 in 5 children with unfavorable vision (84\%) but less than half of children with favorable vision $(48 \%)$ were below grade level in school performance. Lower socioeconomic status (SES) and minority status were associated with lower-grade performance and utilization of special education services across both visual outcome groups. Table 3 also highlights that over $95 \%$ of extremely preterm survivors do not experience blindness.

\subsection{Cognitive Outcomes}

The assessment of cognitive outcomes can focus on three related domains: intelligence testing, achievement testing, and neuropsychological testing. The latter includes evaluation of specific higher cortical processes such as executive function, working memory, and information processing. Assessment of toddlers and young children combines precursors of verbal and nonverbal intelligence and cognitive processes (e.g., object permanency, symbolic play), whereas schoolage assessment and beyond require more complex testing to assess problem-solving, literacy, and numeracy. There is increased recognition that Bayley II and III scores $<70$ predict complex cognitive and learning challenges among schoolage children. However, among children with 2-year Bayley scores of 71-84 (1-2 standard deviations below the mean), they may be uniquely vulnerable to the lack of quality early childhood education and preschool experiences, especially in socially disadvantaged families (Patrianakos-Hoobler et al. 2009). Therefore, one needs to be cautious in using developmental assessments in the first 2 years of life to fully assess the spectrum of cognitive and learning disorders in all children, not only those preterm and growing up in vulnerable circumstances. The limitations in Bayley assessments are due to the dynamic processes of higher cortical functioning in childhood. Additionally, the assessment of developmental delay is intertwined with perceptual and sensory skills as well as early learning experiences and neuroplasticity. Learning, communication, and social challenges may not 
be apparent until there is increased complexity of tasks for academic skills and behavioral/ attention regulatory capacity required by school environments.

In order to address higher-level skills at school entry, one strategy is to examine children's status at kindergarten entry. EPI cohorts born in the 1980s from Hamilton, Ontario, Melbourne, Australia, Buffalo, New York, and Chicago, Illinois, have demonstrated that $44-56 \%$ require special education resources and 21-29\% have major neurodevelopmental impairments (Baek et al. 2002; Vohr and Msall 1997). These studies indicate that, in addition to planning for major developmental disabilities, resources are required to ensure success with peers in the classroom.

Gross and colleagues followed infants born very preterm and found that $41 \%$ of preterm infants were performing at grade level versus $70 \%$ of term children. These preterm children were more likely to receive special education services and three times as likely to be diagnosed with learning disabilities. In this cohort, parental marital status and educational attainment were significantly related to educational outcomes (Gross et al. 2001). Nearly three times as many preterm children achieved grade-level performance if parents were married as compared to children from single-parent homes. Thus, preterm survivors with limited family resources are further disadvantaged and vulnerable.

In Cleveland, Litt and colleagues prospectively followed 219 surviving ELBW children born between 1992 and 1995 through middle childhood and adolescence. Surviving children had a mean birth weight of $815 \mathrm{~g}$, a mean GA of 26.4 weeks; and almost 1 in 5 was from multiple birth gestations. Neonatal morbidities included bronchopulmonary dysplasia in $41 \%$, sepsis in $29 \%$, and sonographic parenchymal brain injury in 24\% (IVH3-IVH4/PVL by cranial ultrasound). Importantly, 115 term controls from the extremely preterm survivor's community classroom were assessed at 14 years. Both the extremely preterm survivors and a prospectively recruited term control group underwent a comprehensive neuropsychological battery that included reading and mathematics and neuropsychological skills of processing speed, attention, visual memory, working memory, and planning. In addition, social capital as determined by maternal education and median household income as well as gender and minority status was used as covariates when analyzing predictors of high school functioning (Litt et al. 2012).

Though major neurosensory disabilities occurred in approximately 1 in 6 of ELBW survivors (CP $15 \%$, blindness in $0.5 \%$, and hearing loss requiring amplification in $1.7 \%$ ), a far greater number of children experienced ID and cognitive impairments. More than 1 in $6(18 \%)$ had ID (IQ < 70), a 4.5-fold greater risk than for term peers. More than 1 in 3 (37\%) were cognitively impaired (IQ 71-84), a 2.3-fold greater risk than for term peers. Most importantly, almost 1 in 2 (49\%) of ELBW survivors required an individualized educational plan, a fivefold higher rate than term peers. The educational resources required for managing these highly prevalent disorders would require an additional $\$ 50,000$ per child during their high school years for tutoring, smaller class size, and specific curriculum modifications (Msall 2012).

Of concern were the achievement challenges of extremely preterm survivors who experienced socioeconomic adversity. These children not only demonstrated a 6.6-point lower IQ but had standard scores that were 10 points lower in reading and 8 points lower in mathematics. Importantly, both executive function and visual memory challenges were associated with academic struggles in reading and mathematics (Johnson et al. 2009, 2011; Simms et al. 2015; Wolke et al. 2015).

\subsubsection{What Does This Mean?}

The first lesson brings optimism: the large majority of ELBW survivors (83\%) are free of neurosensory disability. Thus, unprecedented survival without major neurosensory disability can be expected. However, despite antenatal corticosteroids, surfactant replacement, improved nutrition, and infection control, the rates of $\mathrm{CP}$ are over 100-fold greater than for term infants. Thus, ongoing efforts in neuroprotection remain a scientific, clinical, and political priority.

The second lesson is sobering: the majority of ELBW survivors experience ongoing and 
serious challenges in learning, coordination, and executive function. These children benefit from quality and comprehensive interventions and special educational accommodations with continued review of how these services promote literacy, numeracy, and life skills. Litt and colleagues' outcomes suggest that evidence-based psychoeducational management strategies for executive function and specific learning disorders may be key areas for maintaining children on positive developmental trajectories (Litt et al. 2012). An important challenge in the upcoming decade is to comprehensively implement, at a population level, appropriately targeted developmental and educational optimization strategies for all preterm survivors. With more developmentally appropriate individual- and population-level supports, their neurodevelopmental risks that currently result in costly and adverse long-term physical, behavioral, educational, and social health outcomes could be dramatically reduced.

\subsubsection{Behavioral/Emotional Disorders}

Behavioral and emotional disorders are more prevalent among children born premature compared to their term birth peers. Meta-analysis of behavioral outcomes by Bhutta and colleagues revealed that children born preterm have a 2.6fold risk for developing attention-deficit hyperactivity disorder (ADHD) during school age (Bhutta et al. 2002). These children are also at high risk for externalization problems such as aggression, oppositionality, and disruptive behaviors, which also are major obstacles in establishing friendships or other social relationships (e.g., lack of patience in waiting for their turn in group play) (Farooqi et al. 2007; Saigal et al. 2003). In these studies, birth weight, family function, gender, and SES predicted the behavioral adjustment of adolescents who survived ELBW status in the 1980s or the middle childhood behavioral and childhood behavioral and social adjustment of children who survived 23-25 weeks of gestation in the 1990s.

An important discovery occurred over the past decade whereby it was noted that very and extremely preterm infants were at high risk for delays in social-emotional behavioral regulation that manifested as hyperactivity, impulsivity, and difficulty with social competencies in the preschool years (Jones et al. 2013). Importantly, those children receiving appropriate quality preschool education experiences were more ready for kindergarten both cognitively and behaviorally than those who did not access these services (Arpi and Ferrari 2013; Treyvaud et al. 2013). There has also been increased recognition that late preterm survivors are at risk for regulatory and social challenges. Recent comparative investigations of toddler outcomes for LPI versus other premature infants demonstrate more externalizing, oppositional, and aggressive behaviors, suggesting a unique vulnerability for LPIs (Shah et al. 2013). Infants more prone to distress who also experienced more critical parenting styles in infancy were more likely to demonstrate externalizing behaviors at age 3, suggesting that characteristics of both infants and parents influence preterm vulnerability (Poehlmann et al. 2012).

There has also been an increased awareness of the vulnerability of adolescent and adult survivors of very and extremely preterm birth to increased rates of behavior and mental health disorders (Gardner et al. 2004). This is highlighted in Table 4. An important review by Johnson and Marlow emphasized a life course health development framework and highlighted the increased risk of attention, socio-communicative (including autism spectrum disorder), and emotional difficulties among extremely preterm survivors (Johnson et al. 2011). Importantly they highlighted rates of autism spectrum disorder (ASD) as high as 1 in 12 EPI survivors as they enter adolescence (Johnson et al. 2011). A New Jersey cohort found a rate of 1 in 20 for ASD in moderate LBW at school exit (Pinto-Martin et al. 2011). Most recently, in a large US cohort of 889 EPI survivors born in 2002-2004, Joseph and colleagues found a rate of ASD in males at age 10 of $9 \%$ and in females of $5 \%$. Rates of ASD were $15 \%$ at 23-24 weeks of gestation, $6.5 \%$ at 25-26 weeks of gestation, and $3.4 \%$ at 27 weeks of gestation (Joseph et al. 2016). 
Table 4 Adolescent and adult behavioral health outcomes

\begin{tabular}{|c|c|c|c|}
\hline Authors & Cohort & Age at assessment & Developmental outcome \\
\hline \multirow[t]{2}{*}{ Botting et al. (1997) } & $\begin{array}{l}\text { 1980-1983 Liverpool, } \\
\text { England }\end{array}$ & \multirow[t]{2}{*}{12 years } & \multirow{2}{*}{$\begin{array}{l}\text { 1. Any psychiatric disorder: } \\
28 \% \text { VLBW vs. } 9 \% \text { controls } \\
\text { had any psychiatric disorder } \\
\text { 2. ADHD: } 23 \% \text { VLBW vs. } 6 \% \\
\text { controls }\end{array}$} \\
\hline & $\begin{array}{l}138 \text { VLBW and } 108 \text { matched } \\
\text { controls }\end{array}$ & & \\
\hline Dahl et al. (2006) & $\begin{array}{l}1978-1989 \\
\text { Norway } \\
99 \text { VLBW }\end{array}$ & $13-18$ years & $\begin{array}{l}\text { 1. VLBW adolescents report } \\
\text { less externalizing behaviors } \\
\text { than NBW adolescents } \\
\text { 2. Parents of VLBW } \\
\text { adolescents report more } \\
\text { externalizing behaviors and } \\
\text { emotional problems than NBW } \\
\text { adolescents. }\end{array}$ \\
\hline Grunau et al. (2004) & $\begin{array}{l}\text { 1981-1986 } \\
\text { British Columbia } \\
79<800 \text { g vs. } 31 \text { term }\end{array}$ & 17 years & $\begin{array}{l}\text { 1. No differences for focus and } \\
\text { attention } \\
\text { 2. Significantly more parental } \\
\text { reported internalizing, } \\
\text { externalizing, and problem } \\
\text { behaviors }\end{array}$ \\
\hline Jong et al. (2012) & $\begin{array}{l}\text { Meta-analysis of moderate } \\
\text { and late preterm } \\
(32-36 \text { weeks) } \\
28 \text { papers reviewed }\end{array}$ & $\begin{array}{l}\text { Not reported } \\
\text { (meta-analysis) }\end{array}$ & $\begin{array}{l}30 \% \text { higher psychiatric } \\
\text { disorders }\end{array}$ \\
\hline Kunugi et al. (2001) & $\begin{array}{l}\text { Meta-analysis of LBW and } \\
\text { schizophrenia prevalence; } \\
750 \text { with schizophrenia and } \\
29,000 \text { control subjects }\end{array}$ & $\begin{array}{l}\text { Not reported } \\
\text { (meta-analysis) }\end{array}$ & $\begin{array}{l}\text { LBW prevalence: } 9.5 \% \text { of } \\
\text { schizophrenics and } 3.9 \% \text { of } \\
\text { controls }\end{array}$ \\
\hline $\begin{array}{l}\text { Levy-Shiff et al. } \\
\text { (1994) }\end{array}$ & $\begin{array}{l}\text { Israel } \\
90 \text { VLBW and } 90 \mathrm{NBW}\end{array}$ & $13-14$ years & $\begin{array}{l}\text { Significantly increased } \\
\text { hyperactive behavior among } \\
\text { VLBW. However paternal } \\
\text { involvement was as predictive } \\
\text { as birth weight for } \\
\text { hyperactivity in childhood }\end{array}$ \\
\hline Saigal et al. (2006) & $\begin{array}{l}\text { 1977-1982 } \\
\text { Ontario, Canada } \\
166 \text { ELBW and } 145 \text { NBW }\end{array}$ & $22-25$ years & $\begin{array}{l}1.3 \% \text { of ELBW had autism vs. } \\
0 \% \text { controls }\end{array}$ \\
\hline Saigal et al. (2007) & $\begin{array}{l}\text { Ontario, Canada } \\
149 \text { ELBW and } 133 \mathrm{NBW}\end{array}$ & 23 years & $\begin{array}{l}14.1 \% \text { ELBW vs. } 6 \% \text { on } \\
\text { antidepressants }\end{array}$ \\
\hline
\end{tabular}

\subsubsection{What Does This Mean?}

The current understanding of the vulnerabilities of the preterm infant brain to challenges in coordination, learning, attention, and social skills offers opportunities for understanding cumulative risk and protective strategies linked to biomarkers and neurometrics. The goal of understanding what supports are needed to protect the vulnerable preterm infant brain for learning regulatory, attention, executive function, and social competencies will require increased attention to how active health and developmental experiences shape these developmental processes and what proactive informed interventions support success academically, behaviorally, and socially. Revolutionary strategies in developmental neuroscience will help inform an evidence-based approach to early identification and intervention so that children stay on track in development. In many ways, children with prematurity can help inform a shift from categorizing children's delays as leading to low learning expectations. We can examine how 
attention, regulatory, and social skills can be modified and lead to pathways of resilience in academic achievement and social-emotional behavioral competencies.

\section{$5 \quad$ Chronic and Acute Stress}

Recent studies have produced a large body of evidence that stress is significantly correlated with the occurrence of adverse birth outcomes, including prematurity and low birth weight (GraignicPhilippe et al. 2014). Prenatal stressors can include physical and psychological stress, infections, nutritional deficiencies, and drug exposures (Bock et al. 2015). In a prospective study, Killingworth-Rein et al. combined three variables into a single stress indicator comprised of state anxiety, perceived chronic stress, and life event distress. Higher scores on this aggregated factor predicted a shortened gestation and lower birth weight (Rini et al. 1999). Torche and Kleinhaus (2012) found that females who were exposed to earthquakes in early pregnancy had higher rates of preterm delivery (Torche and Kleinhaus 2012). In a study in the southern Israeli town of Sderot (4 km away from the Gaza Strip), Wainstock et al. hypothesized that the frequent exposure to rocket attacks in this community would be associated with adverse birth outcomes when compared to Kiryat Gat, a similar town without constant rocket attack exposure. Researchers found that women living in Sderot gave birth to more babies born preterm and at low birth weight, confirming the hypothesis that stress in pregnancy increases adverse birth outcomes (Wainstock et al. 2014).

A number of other studies have demonstrated an association between prenatal stress and adverse pregnancy and birth outcomes, including effects on birth weight, gestational age, and preterm birth (Bock et al. 2015). Chronic stress and acute stress may exert different effects on fetal development and perinatal outcomes. Several authors have reported lower birth weight and shortened gestation in children born to mothers exposed to chronic stress compared to acute stress (Chrousos and Gold 1992; Rini et al. 1999; Sable and Wilkinson 2000; Wadhwa et al. 1996).
Likewise, there is increasing evidence that exposure to forms of toxic stress in early life alters stress responses in adulthood. A case-controlled longitudinal study of preterm and term infants with and without medical complications demonstrated dysregulation of the hypothalamic-pituitaryadrenal axis in adult survivors of prematurity, particularly survivors also exposed to socioeconomic disadvantage (Winchester et al. 2016).

There is also a strong association between specific early pregnancy events, such as complications in the first trimester, and increased risk of preterm delivery and very preterm delivery (van Oppenraaij et al. 2009). An increased risk of low birth weight and very low birth weight was associated with first-trimester bleeding in a large prospective study (M. A. Williams et al. 1991). These adverse infant outcomes were associated with threatened miscarriage in the first trimester in another large retrospective study (Wijesiriwardana et al. 2006).

\section{Epigenetic Mechanisms}

Although the mechanisms of prenatal stress are not precisely known, it has been proposed that the hypothalamic-pituitary-adrenal (HPA) axis and sympathetic nervous system stress responses could lead to complications in pregnant women during pregnancy and delivery (GraignicPhilippe et al. 2014). In particular, McLean et al. (1995) suggest that high levels of neurohormones in the HPA axis as well as placental neurohormones could induce prematurity. A growing body of evidence suggests that epigenetic mechanisms induce transient and permanent alterations in gene function, resulting in altered developmental processes in the brain that result in long-term changes in emotional and cognitive behaviors (Bock et al. 2015).

The main function of the epigenome is to regulate gene transcription and compaction of DNA into the cell nucleus through mechanisms such as DNA methylation and hydroxymethylation, histone modifications, ATP-dependent chromatin remodeling, and noncoding RNAs (Provencal and Binder 2015). Prenatal stress has been shown 
to reduce the expression and activity of the enzyme 11- $\beta$-hydroxysteroid dehydrogenase type 2, an enzyme that converts glucocorticoids into inactive metabolites (Bock et al. 2015). An alteration in placental permeability may lead to excess exposure to maternal stress hormones, thereby promoting developmental dysregulation. Maternal intake of steroid hormones (Marciniak et al. 2011), maternal depression (O'Connor et al. 2014), and maternal anxiety (Kane et al. 2014) have been shown to alter maternal glucocorticoid levels, with a high correlation between maternal and fetal plasma glucocorticoids (Provencal and Binder 2015). In addition to affecting birth outcomes, stressful experiences in utero or during early life may also increase the risk of neurodevelopmental and behavioral disorders later in life due to alterations in epigenetic regulation (Babenko et al. 2015).

Pregnant mothers who have anxiety disorders, post-traumatic stress disorder (PTSD), depressive disorders, or major psychoses are at higher risk of adverse birth outcomes including preterm birth, low birth weight, and small-for-gestationalage infants. Mothers with bipolar disorder are at twice the risk for these adverse outcomes (MacCabe et al. 2007). Importantly, pregnant mothers with both PTSD and major depressive episode have four times the risk of having a preterm birth (Yonkers et al. 2014).

These risks occur because the brain and placenta are closely linked by a number of peptides and proteins, including oxytocin, somatostatin, neurotensin, encephalin, cortisol, insulin-like growth factor 1, vascular endothelial growth factor, and cyclic AMP response element binding factor. Individuals with mental illness often have a tendency toward coagulation and low activity of tissue plasminogen activator, potentially contributing to placental insufficiency that may lead to increased exposure of the fetus to maternal hormones. Hyperemesis gravidarum, a condition more common in women with eating disorders and anxiety than in controls, is another risk factor for pregnancy complications which may increase the risk of miscarriage, low birth weight infants, and preterm infants (Hoirisch-Clapauch et al. 2015).

\section{$7 \quad$ Prenatal Stress Reduction Strategies}

Intervention programs aimed at reducing stress should be considered to potentially lower the rates of unfavorable pregnancy outcomes (Wainstock et al. 2014). Feinberg et al. examined the effects of family foundation (FF), a transition to parenthood program, through a randomized control study of 148 expectant mothers. Researchers showed that the intervention significantly reduced the negative impact of maternal cortisol on birth weight, gestational age, and days in hospital in infants, thereby decreasing the risk for adverse birth outcomes (Feinberg et al. 2015). Follow-up at age 5-7 years demonstrated improved outcomes in behavior regulation and children's school adjustment (Feinberg et al. 2014). It is important to recognize the extent to which a child is affected by a mother's stress, and mental health heavily depends on moderating factors that include quality of parenting, social support, and the length and severity of the parental disorder (Howard et al. 2014). In this respect, early identification and interventions are essential (Stein et al. 2014). A recent report estimated that the long-term economic costs of perinatal mental disorders for each annual cohort exceed 8 billion euros in the UK alone (Bauer et al. 2014). Early interventions for perinatal mental disorders could produce great economic benefits and improve maternal and child physical and mental health (Howard et al. 2014) via impacting on child's regulatory behaviors and learning opportunities.

\section{The Impact of Fetal Environment and Prematurity on Adult Health Outcomes}

Exposure to an unfavorable environment in early life is closely associated with an increased tendency to develop adult disease. In 1992, David Barker hypothesized that the period of pregnancy and the intrauterine environment have a profound impact on risk of developing diseases 
like hypertension; diabetes; cardiac, pulmonary, and renal diseases; and mental illness (Capra et al. 2013). Intrauterine environment and early postnatal life are now generally accepted as important factors that may lead to increased risk for disease in adulthood (Hofman et al. 2004). In particular, low birth weight, a marker of poor fetal growth, is linked to vascular disease, hypertension, obesity, and insulin resistance (Calkins and Devaskar 2011).

Although several studies have reported an association between low birth weight and poor adult health outcomes, it remains unclear whether this association exists for children with poor fetal growth born small for gestational age as well as premature babies whose weight is appropriate for gestational age. In a retrospective study, Kaijser et al. identified subjects born preterm or with a low birth weight at four major delivery units in Sweden from 1925 to 1945 . Researchers found that future risk for ischemic heart disease was most closely mediated by fetal growth restriction instead of preterm birth without growth restriction. Of note, these results came from a 1925 to 1949 birth cohort, a period when infants did not benefit from modern neonatal care. During more recent decades, infant survival has improved substantially for children born very preterm. It may not be appropriate, therefore, to generalize these results to preterm and growth-restricted infants being born today (Kaijser et al. 2008).

Babies born prematurely, whether or not they have intrauterine growth restriction (IUGR), are also at risk as adults for poor cardiovascular health outcomes (Irving et al. 2000). In a study of mothers of $72 \mathrm{LBW}$ and $54 \mathrm{NBW}$ infants born in Edinburgh between November 1973 and February 1975, LBW premature babies had higher adult blood pressure and fasting plasma glucose than NBW controls born at term. Babies born prematurely also had trends for an adverse metabolic profile and were at risk for hypertension and hyperglycemia as adults. Infants with IUGR were not measurably more disadvantaged than preterm infants with birth weight appropriate for gestational age (Irving et al. 2000).

A prospective follow-up study of 458 adults at age 30 in New Zealand also aimed to distinguish the relative contributions of gestation length and fetal growth to cardiovascular risk factors in adulthood. Preterm birth, rather than poor fetal growth, was shown to be the major determinant of the association between early environment and adult health outcomes; adults born preterm had increased systolic blood pressure and insulin resistance at age 30 . Birth weight, independent of gestational age, was not associated with increased adult systolic blood pressure and insulin resistance, suggesting that length of gestation may be the major contribution to cardiovascular risk in adulthood (Dalziel et al. 2007).

Adult-onset insulin resistance, an early marker for type 2 diabetes, is also associated with premature birth (Hofman et al. 2004). Exposure to an adverse environment may be responsible for this reduction to insulin sensitivity, whether during intrauterine life in infants small for gestational age or a primarily adverse postnatal environment in premature infants (Hofman et al. 2004).

For the most part, mechanisms to explain the associations between intrauterine and postnatal environments and adult health outcomes are unknown. It is hypothesized that alterations to the HPA axis may explain the link between low birth weight and later increased blood pressure (Dalziel et al. 2007). Furthermore, it is theorized that earlier maturation of organ system exposure to nutritional, metabolic, hormonal, sensory, and respiratory environments at earlier time points in premature babies may also lead to abnormal development of organ systems involved in cardiovascular health (Curhan et al. 1996). Preterm infants and small-for-gestational-age infants often experience a period of "catchup growth" in the postnatal period, which may influence changes in their metabolism that are related to increased risk for these diseases (Smith and Ryckman 2015).

Increasing preterm infant survival has critical implications on the burden of adult diseases such as diabetes and cardiovascular disease. In fact, the historic trends in preterm survival and birth may be playing a critical, yet underappreciated, role in the population trend toward increasing prevalence of diabetes and cardiovascular disease (Dalziel et al. 2007). 


\section{$9 \quad$ Postnatal and Social Risk}

Despite knowledge that supports that intervention in early childhood can positively impact disability trajectories, large gaps in services exist and disproportionally impact disadvantaged families. A 1997-2000 study looked at access to early intervention services among a population of infants aged birth to 3 years. Even in the highest risk neonates, access to community and early intervention supports was problematic and fragmented at best ( $>40 \%$ not enrolled in early intervention). Those toddlers with higher rates of disability were more likely to receive more services, yet a significant unmet need for services was documented among milder cases (Hintz et al. 2008).

Second, a Chicago-based cohort was followed after NICU discharge and demonstrated that less than $60 \%$ of VLBW infants living in extreme poverty $(<50 \%$ federal poverty level $)$ were receiving early intervention (EI) services despite having access to a medical home and legal advocacy. Of the 415 infants deemed not automatically eligible by EI, 95\% had child and family impairments (e.g., gastrostomy, feeding delays, income $<\$ 10 \mathrm{~K}$ per year, parental mental or developmental disorder) that met EI inclusion criteria. This data confirms that a substantial number of infants with multiple medical and social risks do not receive ongoing developmental surveillance or early intervention services (Weiss et al. 2007).

Third, in a recent analysis of the Early Childhood Longitudinal Survey-Birth Cohort, it was found that eligibility for Part $\mathrm{C}$ varied widely between states (2-78\%), yet the proportion of children receiving services remained consistently low $(1.5-7 \%)$. There is significant state-by-state variability between eligibility criteria, yet there is also a clear national trend of insufficient enrollment for children with qualifying delays (Rosenberg et al. 2008). Given that in elementary school years 10-20\% of children nationally have Individual Educational Plans, early intervention rates less than 5\% reflect significant missed opportunities for secondary and tertiary prevention.

Among both VLBW and ELBW survivors, disproportionate numbers live in communities with high rates of school dropouts and poorly per- forming schools. This will result in barriers to accessing quality early and middle childhood educational experiences. The combination of developmental vulnerability due to LBW and preterm birth with social and family distress has shown to have cumulative impacts (Hille et al. 1994). In an 8-10-year follow-up study of infants who were the sickest and tiniest and had the most medical complications in the newborn period, Msall and colleagues found that not only were favorable vision and functional motor status at kindergarten entry associated with significantly lower rates of special education and below-gradelevel educational achievement, but higher SES was also associated with positive academic and developmental outcomes. Factors strongly associated with increased risk for special education services included minority status, poverty, lack of access to a car, and Supplemental Social Security Income because of disability and poverty (Msall et al. 2004).

\subsection{Adolescent and Adult Outcomes}

Clinical research to date on the outcomes for preterm infants during adolescence and adulthood reveals a spectrum of strengths and challenges in physical and behavioral health, educational achievement and supports, and community participation. However, the social, educational/vocational, and independent adaptive life skills required for adulthood are inherently more quantitatively and qualitatively complex than basic developmental milestones in an infant or school achievement in middle childhood. A few crude measures of adult success have been used to examine adolescent and adult outcomes, but much work remains to unveil more meaningful multidimensional measures of adult physical and behavioral health, daily functioning, social participation, family formation, and economic well-being.

Educational attainment is a frequently examined adult outcome in the literature. The studies highlighted in Table 5 demonstrate lower rates of academic achievement, high school completion, and postsecondary education among preterm survivors. Premature survivors show high rates of 
Table 5 Cognitive, executive function and academic achievement in adolescence and adulthood

\begin{tabular}{|c|c|c|c|}
\hline Authors & Cohort & Assessment age & Developmental outcome \\
\hline Botting et al. (1998) & $\begin{array}{l}\text { 1980-1983 Liverpool, } \\
\text { England } \\
138 \text { VLBW } \\
108 \text { matched controls }\end{array}$ & 12 years & $\begin{array}{l}\text { 1. VLBW lower IQ } \\
\text { 2. Lower math and reading } \\
\text { comprehension }\end{array}$ \\
\hline Saigal et al. (2000) & $\begin{array}{l}\text { 1977-1982 } \\
\text { Ontario, Canada } \\
141 \text { ELBW } \\
124 \text { matched controls }\end{array}$ & $12-16$ years & $\begin{array}{l}\text { 1. } 28 \% \text { reported neurosensory } \\
\text { impairments } \\
\text { 2. } 25 \% \text { of ELBW vs. } 6 \% \text { repeated a } \\
\text { grade } \\
\text { 3. } 49 \% \text { of ELBW vs. } 10 \% \text { required } \\
\text { special education services } \\
\text { 4. } 22 \% \text { ELBW required full-time } \\
\text { educational assistance (vs. } 0 \% \text { ) } \\
\text { 5. Lower mean WISC-R DQ } \\
\text { 6. Lower mean WRAT-R }\end{array}$ \\
\hline Rushe et al. (2001) & $\begin{array}{l}\text { 1979-1980 } \\
\text { London, England } \\
<33 \text { weeks; } 75 \\
\text { premature and 53 FT }\end{array}$ & 14-15 years & $\begin{array}{l}\text { 1. No differences for tests of executive } \\
\text { function, verbal memory, attention } \\
\text { 2. Preterm group had impaired verbal } \\
\text { fluency }\end{array}$ \\
\hline Lefebvre et al. (2005) & $\begin{array}{l}\text { 1976-1981 } \\
\text { Montreal, Canada } \\
57 \text { ELBW and } 44 \text { NBW }\end{array}$ & 18 years & $\begin{array}{l}\text { 1. } 56.1 \% \text { ELBW vs. } 84.6 \% \text { controls } \\
\text { completed HS } \\
\text { 2. } 33 \% \text { vs. } 9 \% \text { required special } \\
\text { education } \\
\text { 3. Significant differences in low IQ } \\
(<85)\end{array}$ \\
\hline Hack et al. (2002) & $\begin{array}{l}\text { 1977-1979 } \\
\text { Cleveland, Ohio } \\
242 \text { VLBW and } 233 \\
\text { controls }\end{array}$ & 20 years & $\begin{array}{l}\text { 1. } 74 \% \text { VLBW graduated HS vs. } 83 \% \\
\text { NBW } \\
\text { 2. } 30 \% \text { pursued secondary education vs. } \\
53 \% \text { NBW } \\
\text { 3. } 40 \% \text { repeated grade vs. } 27 \% \text { NBW } \\
\text { 4. Scored } 1 / 3 \text { SD lower on WAIS-R }\end{array}$ \\
\hline $\begin{array}{l}\text { Lindstrom et al. } \\
\text { (2009) }\end{array}$ & $\begin{array}{l}\text { 1973-1979 } \\
\text { Sweden } \\
\text { 24-28 weeks vs. FT }\end{array}$ & $\begin{array}{l}\text { 1987-2002 national } \\
\text { registry }\end{array}$ & $\begin{array}{l}71 \% \text { vs. } 78.6 \% \text { completed } 12 \text { or more } \\
\text { years of school }\end{array}$ \\
\hline Moster et al. (2008) & $\begin{array}{l}1976-1983 \\
\text { Norway } \\
325 \text { preterm }(23- \\
27 \text { weeks }) \text { vs. } 828,227 \\
\text { FT }\end{array}$ & $20-36$ years & $\begin{array}{l}\text { 1. } 67.7 \text { preterm vs. } 75.4 \% \text { completed } \mathrm{HS} \\
\text { 2. } 4.4 \% \text { preterm vs. } 0.1 \% \text { fullterm with } \\
\text { ID }\end{array}$ \\
\hline $\begin{array}{l}\text { Nomura et al. (2009) } \\
\text { Johns Hopkins } \\
\text { Collaborative } \\
\text { Perinatal Study }\end{array}$ & $\begin{array}{l}\text { 1960-1965 } \\
\text { Baltimore } \\
226 \text { near-term and } 1393 \\
\text { FT }\end{array}$ & $27-33$ years & $\begin{array}{l}\text { 1. Near-term birth associated with lower } \\
\text { adult educational attainment only for } \\
\text { those living below poverty line } \\
\text { 2. SGA had no association with } \\
\text { educational attainment }\end{array}$ \\
\hline Saigal et al. (2006) & $\begin{array}{l}\text { 1977-1982 } \\
\text { Ontario, Canada } \\
166 \text { ELBW and } 145 \\
\text { controls }\end{array}$ & $22-25$ years & $\begin{array}{l}\text { No significant difference in: } \\
\text { 1. \% graduation from high school } \\
\text { 2. Pursuit of postsecondary education }\end{array}$ \\
\hline
\end{tabular}

$H S$ high school, SD standard deviation, WAIS-R Wechsler Adult Intelligence Scale-Revised, WISC-R Wechsler Intelligence Scale for Children-Revised, $D Q$ deviation quotient, WRAT-R Wide Range Achievement Test-Revised, FT full term

need for special education supports, both in general special education services and with individual assistants, and have higher rates of grade repetition than their normal birth weight peers
(Saigal et al. 2003). Furthermore, preterm survivors are less likely to graduate high school and pursue secondary education (Hack et al. 2002; Moster et al. 2008). 
However, this outcome is also influenced by contextual factors. When high school graduation rates are adjusted for parental SES, there is evidence of mitigation of the difference in educational attainment. In a study by Nomura et al., it was found that in near-term survivors, only those living at incomes close to poverty line differed from full-term peers on educational attainment. The relationship between cognitive testing in adulthood and gestational age has also been significantly mitigated by socioeconomic factors (Ekeus et al. 2010). There is compelling evidence that the same risk factors disproportionately distributing premature birth to poorer, less educated mothers are also at play with the long-term outcomes of low birth weight progeny, compounding the disadvantage of the disadvantaged.

IQ outcomes have been repeatedly tested and show consistently lower scores for ELBW adults compared to matched peers. However, many studies are unable to match for socioeconomic status or parental IQ which are highly influential mediating factors. Maternal education and income have been shown consistently to predict IQ within these cohorts, indeed often with stronger correlation coefficients than LBW status (Drillien 1961; Drillien et al. 1980). There is evidence that IQ in middle childhood is strongly predictive of IQ at adolescence, suggesting that, on this measure, there is neither increasing gap nor improved catch-up to normal birth weight peers. Alternatively, one study highlighted a widening IQ gap in later childhood (Botting et al. 1998), which may be due to the complexity of the involved intellectual task in testing at older ages or the additional components of social/emotional intelligence, which are not entirely captured by younger measures of IQ. Furthermore, studies that evaluate both educational and professional attainment do not consistently demonstrate strong correlation; $50 \%$ of preterm adults in the 1983 Dutch cohort who reported poor educational attainment during the school years held full-time employment as young adults (Hille et al. 2007). How this translates to US cohorts in the ongoing economic crisis for those without college degrees is yet unknown. Other educational outcomes, such as reading and math achievement, have shown significant gaps in core educational outcomes between VLBW and agematched peers. However given that many term children in low-income urban or rural communities in the United States also are struggling with reading, mathematics, science, and social studies performance, it is difficult to make international comparisons.

Additional evidence demonstrates the power of socioeconomic status in modifying the effect of prematurity; Lefebvre et al. assessed the cognitive and academic achievement outcomes in early adulthood of a cohort of 82 ELBW subjects in Montreal (Lefebvre et al. 2005). There were significant differences between ELBW and NBW groups in full-scale IQ (94 versus 108), verbal IQ (93 versus 106), and performance IQ (97 versus 109). However, father's low socioeconomic status contributed significantly to the prevalence of IQ $<85$ (19\% versus $2 \%, p=0.012)$, schooling in mainstream education with a regular curriculum for age (36\% versus $68 \%$ ), requirement for special classes or schools (33\% versus 9\%), and high school graduation for those 18 years or older $(56 \%$ versus $85 \%)$.

Adolescent/adult self-perceptions of health, quality of life, and overall functioning are important outcomes, which may guide our clinical understanding and facilitate improved anticipatory guidance to families of premature neonates. A socioeconomically diverse cohort of adolescents born in 1983-1984 at $<801 \mathrm{~g}$ (Brown et al. 2003) reported themselves and was reported by their parents as having lower functional status than normal birth weight peers; however, overall these health concerns did not significantly interfere with tasks of daily living. On rating scales of externalizing and internalizing problems, however, (The Behavioral Assessment System for Children- BASC), there were no differences between preterm and comparison groups. Additionally, using a self-perception profile, which included domains of scholastic competence, social acceptance, athletic competence, and global self-worth, responses did not significantly differ. In a similar cohort of adults (born at weight $<1250 \mathrm{~g}$ in Zurich), preterm and term controls did not differ on overall physical health 
Table 6 Adult outcomes after very preterm birth

\begin{tabular}{|c|c|c|c|}
\hline Authors & Cohort & Age at assessment & Developmental outcome \\
\hline $\begin{array}{l}\text { Baumgardt et al. } \\
(2012)\end{array}$ & $\begin{array}{l}1983-1985 \\
\text { Zurich, Switzerland } \\
52 \text { preterm }(<1250 \mathrm{~g}) \\
75 \text { controls }\end{array}$ & 23 years & $\begin{array}{l}\text { No difference in overall self-reported } \\
\text { quality of life }\end{array}$ \\
\hline Hack et al. (2007) & $\begin{array}{l}\text { 1977-1979 } \\
\text { Cleveland, Ohio } \\
241 \text { VLBW } \\
232 \text { NBW }\end{array}$ & 20 years & $\begin{array}{l}\text { 1. No difference on self-reported } \\
\text { health satisfaction } \\
\text { 2. No difference on self-reported } \\
\text { comfort (physical or emotional) } \\
\text { 3. Decreased self-reported resiliency } \\
\text { 4. Increased self-reported risk } \\
\text { avoidance }\end{array}$ \\
\hline Hille et al. (2008) & $\begin{array}{l}1983 \\
\text { Netherlands } \\
959 \text { adult survivors of } \\
\text { prematurity (<32 weeks } \\
\text { or VLBW) }\end{array}$ & 19 years & $\begin{array}{l}\text { 1. } 11.4 \% \text { had moderate/severe } \\
\text { problem with profession } \\
\text { 2. } 1 / 2 \text { of individuals with moderate/ } \\
\text { severe problems in education had } \\
\text { full-time employment }\end{array}$ \\
\hline Moster et al. (2008) & $\begin{array}{l}\text { 1976-1983; Norway } \\
325-23-27 \text { weeks } \\
1608-28-30 \text { weeks } \\
6363-31-33 \text { weeks } \\
\text { 31,169- } 34-36 \text { weeks } \\
828,227-\text { full term }\end{array}$ & 20-36 years & $\begin{array}{l}\text { 1. } 10.6 \% \text { vs. } 1.7 \% \text { receiving } \\
\text { disability pension } \\
\text { 2. Lower gestation less likely to have } \\
\text { found life partner } \\
\text { 3. Lower gestation less likely to have } \\
\text { children }\end{array}$ \\
\hline Saigal et al. (2006) & $\begin{array}{l}1977-1982 \\
\text { Ontario, Canada } \\
166 \text { ELBW and } 145 \\
\text { controls }\end{array}$ & $22-25$ years & $\begin{array}{l}\text { No significant difference in rates of: } \\
\text { 1. Employment } \\
\text { 2. Independent living } \\
\text { 3. Married/cohabitation } \\
\text { 4. Parenthood }\end{array}$ \\
\hline
\end{tabular}

$V L B W$ very low birth weight $(<1500 \mathrm{~g}), E L B W$ extremely low birth weight $(<1000 \mathrm{~g}), N B W$ normal birth weight (>2500 g), CPT Conners' continuous performance task

or mental health scores on the Short Form 36 Health Survey (Baumgardt et al. 2012) (Table 6).

Adult males who survived prematurity rated themselves significantly lower than male term adults on the "physical functioning domain," but females did not differ from matched controls in any subset. Patterns of high risk and protective health habits varied: the use of marijuana was significantly lower among adults who survived prematurity, yet significantly more control adults practiced sports and more males exercised. The overall trend appears that adolescents and adult survivors of prematurity, by and large, consider themselves similar to normal term survivors on self-ratings of physiologic and psychological functioning. Some studies suggest that females may be more similar to full-term peers than males, suggesting that males may be somewhat more vulnerable to the long-term effects of prematurity and LBW. It deserves mentioning that the discrepancy between self-reported health and external measures of health has been reported in other health conditions; overall persons with a health condition rate the impact of that condition more positively than health professionals may surmise (Groot 2000).

Research on long-term consequences of low birth weight has focused on adolescent and early adult life - especially the negative impact of low birth weight on academic achievement, high school graduation and years of school completion, and college attendance. Low birth weight has been linked to these outcomes through the effects of low birth weight on kindergarten preparedness and weak performance in the first few years of schooling. Poor educational performance in subsequent years is negatively linked to both poor school readiness and accomplishment on subsequent school performance and the lingering health effects of low birth weight. The 
latter often includes not only growth and respiratory sequelae but increased vulnerability to a spectrum of neurobehavioral disorders that impact attention and mood. Importantly, buffers for these disorders include attention to caregiver mental health and child behavior health in the context of increasing school and community successes. While longerterm effects of low birth weight, mediated by poor educational performance and continued weak health, are hypothesized, little research has examined the midlife consequences of low birth weight and what factors contribute to thriving.

An additional complexity of measuring adolescent and adult outcomes is the shift of health status reporting from the parent of a premature survivor to the adolescent or adult himself/herself. In an adolescent follow-up of 99 very low birth weight babies born in Norway, there was found to be a significant discrepancy between adolescent and parental reporters, with the overall trend being parents reporting significantly more emotional and behavior problems than the adolescents reported in themselves (Dahl et al. 2006). In these later stages of follow-up, investigators must consider the inherent bias in asking parents vs. adolescents to report on health and behavior.

This research limitation can be remedied through analysis of data from two population datasets that include information on weight at birth and current health and well-being - the Wisconsin Longitudinal Study (WLS) and the Midlife in the United States: A National Study of Health and Well-Being (MIDUS). Additionally, utilizing these cohorts from the United States may help remedy the current data gap between well-tracked international cohorts and the dearth of longitudinal US data. International cohorts, which have lower rates of single parenthood and more homogenous racial ethnic and socioeconomic composition as compared to the United States, dominate the current knowledge base of long-term outcomes for premature babies. Extrapolating from their long-term outcomes likely vastly underestimates the need for social support throughout the life course in the United States. Additionally, international countries with single-payer systems tend to diagnose and provide more consistent social support for persons with disabilities when compared to the fragmented nature of health care in the United States.

The Wisconsin Longitudinal Study (WLS) is a long-term study of a random sample of 10,317 men and women who graduated from Wisconsin high school in 1957. The WLS provides an opportunity to study the life course, intergenerational transfers and relationships, family functioning, physical and mental health and well-being, and morbidity and mortality from late adolescence (in 1957) through early geriatric (in 2008). WLS data also cover social background, youthful aspirations, schooling, military service, labor market experiences, family characteristics and events, social participation, psychological characteristics, and retirement. Survey data were collected from the original respondents or their parents in 1957, 1964, 1975, 1992, and 2004 (when they were approximately at age 64 or 65). The WLS includes endof-life data for members of the cohort who have died. Sibling and twin data for the original respondents, as well as gene-environment interactions from late adolescent to the retirement years, will permit models that separate the effects of family origins from the impact of low birth weight at retirement age.

The first national representative survey of Midlife Development in the United States (MIDUS) was conducted in 1995-1996. MIDUS is a 1994 national sample survey of 7189 randomly chosen adults ages $25-74$ years, as well as 1914 respondents to a separate nationally representative sample of twin pairs. The wide age range of the sample was intended to permit comparisons on persons in their early adult life to those in midlife and old age. The survey permits the assessment of many psychological factors such as personality traits, sense of control, and goal commitments and their linkages to marital status, family structure, socioeconomic standing, social participation, social support, employment status, health status, and health-care utilization. MIDUS respondent follow-ups were conducted from 2002 to 2006, and there were a third round of interviews from 2006 to 2011. This dataset, including sibling data, will permit models that separate the effects of family origins and early 
life experiences from the impact of low birth weight at retirement age and beyond.

\section{Conclusion}

The interdependent challenges of prematurity and socioeconomic risk create numerous hurdles for achieving optimal physical, developmental, and emotional health. With over 50,000 surviving extremely preterm and very preterm infants per year in the United States, we have the equivalent of an ongoing annual polio crisis in the prevaccination era. Not only are many of these children growing up in families that are strapped for material resources, services and time, but our current early intervention and preschool systems are not delivering child health, developmental, and behavioral supports on a population basis. Therefore, there is decreased likelihood that the 325,000 late preterm survivors who annually enter kindergarten will be healthy and ready to learn. Nor will they stay on track during the first three grades, achieving adequate levels of literacy, numeracy, information handling, and social participation; they will need to succeed in school and life. As their development lags and their academic performance falters, there is too often a response of educational systems, especially during the middle school years, to divert children by using grade repetition, expulsions, and nonevidence-based remediation that only increase the likelihood that the child will leave school or be classified with behavioral problems. Importantly, unlike their middle-class and affluent counterparts, low-income children with a spectrum of neurodevelopmental dysfunction will have less access to high-quality medical care, appropriately targeted and responsive parent-child interactions, quality educational accommodations and explicit strategies for promoting basic competencies, and extracurricular activities.

Although potentially detrimental to a child's future, his/her gestational age and birth weight are rarely the major determining factors when long-term educational, social, and behavioral outcomes are considered. In this chapter we have examined several research studies that emphasized the importance of family, social, and economic environmental factors, which can either aggravate or moderate neonatal risks caused by premature birth. Much is to be gained by attention to how adversity impacts allostatic load, and through epigenetic mechanisms and complex protective buffers of parenting, health promotion, and social supports, leads to long-term outcomes of thriving across physical, behavioral, and social health outcomes. With so much to lose while living under suboptimal conditions, it is of critical importance that both health and educational professionals create systems for enhancing access to early childhood learning experiences, parenting supports, quality preschool education services, and biopsychosocial strategies in middle childhood to help children achieve basic educational, behavioral, and social competencies and adolescent supports of mentoring, preparation for independent living, and proactive behavioral health strategies for stress, time management, mood disorders, and self-efficacy. We need more research about how to spread and scale successful biopsychosocial health development strategies at a community level to insure that VLBW and ELBW survivors do not miss out on the critical experiences, which have potential to compensate for birth disadvantage, and are critical for longterm adult success. A summary of the gaps and recommendations for increasing research in life course health development after prematurity follows.

Research in life course health development for children who survive prematurity has made the following advances:

1. Medical advances in pregnancy: Over the past decades, there has been improved management of high-risk pregnancy disorders such as hypertension, diabetes, multiple gestation, intrauterine growth restriction, prenatal infections, and fetal malformations. There has been growing awareness that women's health involving the use of tobacco, alcohol, illicit drugs, anticonvulsants, and antidepressants has subtle neurobehavioral consequences on child development. Additionally, society has 
had greater recognition that poverty, social adversity involving basic resources as well as lack of partner/family supports, previous preterm birth, minority status, limited education, and low health literacy increase the risk of low birth weight, prematurity, and early childhood health and developmental impairments.

2. Medical advances in the neonatal period: Over the last decades, there has been remarkable improvement in the management of premature labor and delivery. In particular, the widespread screening for and treatment of Group B Streptococcus colonization and the use of maternal corticosteroids when preterm labor presents have had marked improvements in premature survival and sequelae of neonatal infections. We have had improved resuscitation and neonatal transport to tertiary care centers. Throughout the vulnerable neonatal course, improved respiratory support (the use of positive pressure and noninvasive ventilator techniques after surfactant), evidence-based nutritional interventions, and infection control management have improved neonatal survival.

Although there is increased recognition that very and extremely preterm survivors experience a variety of health (e.g., growth, pulmonary), neurological (e.g., sensory impairments, seizures), neurodevelopmental (e.g., CP, ID, ASD), and learning and behavior impairment, the population-level risks have not been systematically measured. In order to improve life course health development, we propose seven theme research agenda.

\section{Recommendations for an After Prematurity Life Course Health Disparities Research Agenda}

\section{Establish national registries.}

It is imperative to create national registries for children from birth to 5 years old who are at highest risk of $\mathrm{CP}$ and neurodevelopmental disabilities such as intellectual disability, neu- rosensory disability, and autism spectrum disorders. These registries would not only include preterm infants but also include term infants with history of critical illness from cardiac, pulmonary, infectious, neurological, or genetic disorders. Such registries would allow for the investigation of diverse interventions and link health, early intervention, special education, and rehabilitation services to long-term outcomes across the life course. Most importantly attention must be paid to maternal health, adversity, and mental health. Registries ought to include placental samples as well as cord blood and newborn screening blood spots, in order to allow for the evaluation of early biomarkers of toxic stress during early childhood.

2. Build population-based datasets.

To understand health across the life course, it is imperative to create population-based datasets which originate at delivery and during newborn primary care visits. We must be able to link information on birth certificates with early childhood health, developmental, and educational outcomes through collaborative arrangements between public health, regional neonatal follow-up, early intervention, and district-wide educational testing. We should use these population databases to engage in ongoing health and developmental surveillance of all children with all degrees of prematurity requiring neonatal intensive care, especially those with seizures, neonatal encephalopathy, congenital heart disease, malformation requiring surgery, and abnormalities in newborn genetic and hearing screening. We should model our US efforts on the Longitudinal Study of Australian Children to understand diverse trajectories of health, development, and behavior for those with and without special health-care needs.

Preterm infants need the establishment of longitudinal data collection registries that can collect information that is similar to the National Survey of Children's Health and NHIS disability follow-up studies. We must determine the risk factors for trajectories of positive and negative outcomes across cohorts 
of middle childhood, adolescence, and adulthood for sequential preterm survivors who were $<28$ weeks of gestation, 29-31 weeks of gestation, 32-36 weeks of gestation, and term gestation. Only with informed, collaborative, and comprehensive life course health development registries will we determine ways to support resiliency among preterm offspring of high-risk mothers with respect to health, developmental, educational, and social outcomes over the life course.

3. Expansion and evaluation of comprehensive health and developmental surveillance interventions on a population level.

We need to improve population surveillance for children exposed to high-risk maternal conditions such as hypertension, diabetes, obesity, asthma, seizure disorders, depression, ADHD, anxiety, and maternal use of tobacco, alcohol, and illegal substances. In the setting of these risk factors, we must evaluate what factors promote maternal and child resiliency and promote positive newborn and developmental outcomes. We must understand which factors mitigate the negative effect of these exposures on growth, obesity, developmental delays, and regulatory disorders. We should seek to determine the impact of positive parenting, quality early child education (early intervention, head start preschool programming), and pediatric medical homes especially using neonatal and epigenetic biomarkers.

Surveillance should extend beyond the neonatal period into preschool (ages 2-4 years) to identify young children who lack the basic numeracy, literacy, and social and emotional maturity needed to enter kindergarten ready to learn. Kindergarten is also a key transition for measuring health and developmental status, yet there are no systematic screening modalities in place at kindergarten entry across diverse biomedical and social risks.

4. Integration of twenty-first-century technologies to improve care coordination and integrated health and engage families in time-efficient interventions.
Diagnostic tools such as fidgety movements are shown to have high reliability in detection of future motor delays; texting has been shown to improve parental engagement with early childhood development; and telemedicine has enabled the delivery of highly specialized care to remote or mobility-challenged populations. These growing technologies, increasingly available across socioeconomic populations, must be fully embraced and leveraged for population surveillance and therapeutic interventions.

5. Shift research methodology from antiquated methods studying individuals and parent-child dyads to novel techniques examining clusters of families and communities.

Increasingly we need to better understand the power of parent-child interactions on determining developmental trajectories in conjunction with genetic and epigenetic biomarkers. Furthermore, siblings certainly impact health and development of one another, yet most research fails to consider the contribution of sibling factors. We must seek to develop and improve our research modalities, which look beyond a single child as the unit of measure and examine interrelatedness among family and community factors.

6. Research on impacting parent-child interventions.

A critical need is to formally evaluate the caregiving environment of premature infants and determine how cumulative parent-child interactions impact the child's developmental capacities and parental health and well-being. Examine developmental activities as a part of everyday childcare tasks to promote early parent involvement and positive health and regulatory trajectories.

7. Determine what types of interventions effectively impact maternal mental health in the setting of adversities.

It is incompletely known how maternal mental health stressors (depression, anxiety, isolation, and violence) increase vulnerability of children when they do not receive quality early 
childhood social learning and behavioral supports. Strategies for integrating maternal and child physical and behavioral health have the potential to increase resilience for high-risk populations.

By combining themes from this research agenda to populations involving life course health development and the ICF model for promoting health, functioning, and participation, we have the opportunities to improve thriving after prematurity and measure our impact on longterm health, education, and community costs.

Acknowledgments This work was supported in part by NIH NINR03095 (Sullivan, Msall). Dr. Msall was also supported in part by NIH/NICHD Grant P30 HD0544275 JP Kennedy Intellectual and Developmental Disabilities Research Center and HRSA-DHHS T73 MC 11047 Leadership Education in Neurodevelopmental and Related Disorders Training Program (LEND).

\section{References}

Allen, M. C., Cristofalo, E. A., \& Kim, C. (2011). Outcomes of preterm infants: Morbidity replaces mortality. Clinics in Perinatology, 38(3), 441-454. doi:10.1016/j.clp.2011.06.011.

Aron, L., \& Loprest, P. (2012). Disability and the education system. The Future of Children, 22(1), 97-122.

Arpi, E., \& Ferrari, F. (2013). Preterm birth and behaviour problems in infants and preschool-age children: A review of the recent literature. Developmental Medicine and Child Neurology, 55(9), 788-796. doi:10.1111/dmcn.12142.

Babenko, O., Kovalchuk, I., \& Metz, G. A. (2015). Stressinduced perinatal and transgenerational epigenetic programming of brain development and mental health. Neuroscience and Biobehavioral Reviews, 48, 70-91. doi:10.1016/j.neubiorev.2014.11.013.

Baek, Y., Vohr, B. R., Alksninis, B., Cashore, W. J., Hogan, D. P., \& Msall, M. E. (2002). Kindergarten readiness in very low birth weight (VLBW) children. Pediatric Research, 51(4), 293A.

Bauer, A., Parsonage, M., Knapp, M., Iemmi, V., \& Adelaja, B. (2014). The costs of perinatal mental health problems. London: Cemtre for Mental Health and London School of Economics.

Baumgardt, M., Bucher, H. U., Mieth, R. A., \& Fauchere, J. C. (2012). Health-related quality of life of former very preterm infants in adulthood. Acta Paediatrica, 101(2), e59-e63. doi:10.1111/j.1651-2227.2011.02422.x.

Bhutta, A. T., Cleves, M. A., Casey, P. H., Cradock, M. M., \& Anand, K. J. (2002). Cognitive and behav- ioral outcomes of school-aged children who were born preterm: A meta-analysis. JAMA, 288(6), 728-737.

Bock, J., Wainstock, T., Braun, K., \& Segal, M. (2015). Stress in utero: Prenatal programming of brain plasticity and cognition. Biological Psychiatry. doi:10.1016/j.biopsych.2015.02.036.

Botting, N., Powls, A., Cooke, R. W., \& Marlow, N. (1998). Cognitive and educational outcome of verylow-birthweight children in early adolescence. Developmental Medicine and Child Neurology, 40(10), 652-660.

Brown, K. J., Kilbride, H. W., Turnbull, W., \& Lemanek, K. (2003). Functional outcome at adolescence for infants less than $801 \mathrm{~g}$ birth weight: Perceptions of children and parents. Journal of Perinatology, 23(1), 41-47. doi:10.1038/sj.jp.7210850.

Calkins, K., \& Devaskar, S. U. (2011). Fetal origins of adult disease. Current Problems in Pediatric and Adolescent Health Care, 41(6), 158-176. doi:10.1016/j.cppeds.2011.01.001.

Capra, L., Tezza, G., Mazzei, F., \& Boner,A. L. (2013). The origins of health and disease: The influence of maternal diseases and lifestyle during gestation. Italian Journal of Pediatrics, 39, 7. doi:10.1186/1824-7288-39-7.

Chrousos, G. P., \& Gold, P. W. (1992). The concepts of stress and stress system disorders. Overview of physical and behavioral homeostasis. JAMA, 267(9), 1244-1252.

Crouter, A. C., \& Booth, A. (Eds). (2014). Work-family challenges for low-income parents and their children. Routledge. Abingdon, UK.

Curhan, G. C., Willett, W. C., Rimm, E. B., Spiegelman, D., Ascherio, A. L., \& Stampfer, M. J. (1996). Birth weight and adult hypertension, diabetes mellitus, and obesity in US men. Circulation, 94(12), 3246-3250.

Dahl, L. B., Kaaresen, P. I., Tunby, J., Handegard, B. H., Kvernmo, S., \& Ronning, J. A. (2006). Emotional, behavioral, social, and academic outcomes in adolescents born with very low birth weight. Pediatrics, 118(2), e449-e459. doi:10.1542/peds.2005-3024.

Dalziel, S. R., Parag, V., Rodgers, A., \& Harding, J. E. (2007). Cardiovascular risk factors at age 30 following pre-term birth. International Journal of Epidemiology, 36(4), 907-915. doi:10.1093/ije/dym067.

Diagnostic and Statistical Manual of Mental Disorders: DSM-5. (2013). (5th ed.). Washington, DC: American Psychiatric Association.

Dmowska, A., Andrews, B., Schreiber, M., \& Msall, M. E. (2016). Preterm survivors: Community support to lessen health disparities. In J. Merrick \& L. Rubin (Eds.), Environmental health disparities: Costs and benefits of breaking the cycle. Hauppauge, NY: Nova Publishers.

Drillien, C. M. (1961). A longitudinal study of the growth and development of prematurely and maturely born children. VIII. Morbidity in the age period 2-5 years. Archives of Disease in Childhood, 36, 515-525.

Drillien, C. M., Thomson, A. J., \& Burgoyne, K. (1980). Low-birthweight children at early school-age: A lon- 
gitudinal study. Developmental Medicine and Child Neurology, 22(1), 26-47.

Ekeus, C., Lindstrom, K., Lindblad, F., Rasmussen, F., \& Hjern, A. (2010). Preterm birth, social disadvantage, and cognitive competence in Swedish 18- to 19-yearold men. Pediatrics, 125(1), e67-e73. doi:10.1542/ peds.2008-3329.

Farooqi, A., Hagglof, B., Sedin, G., Gothefors, L., \& Serenius, F. (2007). Mental health and social competencies of 10- to 12-year-old children born at 23 to 25 weeks of gestation in the 1990s: A Swedish national prospective follow-up study. Pediatrics, 120(1), 118133. doi:10.1542/peds.2006-2988.

Feinberg, M. E., Jones, D. E., Roettger, M. E., Solmeyer, A., \& Hostetler, M. L. (2014). Long-term follow-up of a randomized trial of family foundations: Effects on children's emotional, behavioral, and school adjustment. Journal of Family Psychology, 28(6), 821-831. doi:10.1037/fam0000037.

Feinberg, M. E., Roettger, M. E., Jones, D. E., Paul, I. M., \& Kan, M. L. (2015). Effects of a psychosocial couplebased prevention program on adverse birth outcomes. Maternal and Child Health Journal, 19(1), 102-111. doi:10.1007/s10995-014-1500-5.

Gardner, F., Johnson, A., Yudkin, P., Bowler, U., Hockley, C., Mutch, L., et al. (2004). Behavioral and emotional adjustment of teenagers in mainstream school who were born before 29 weeks' gestation. Pediatrics, 114(3), 676-682. doi:10.1542/peds.2003-0763-L.

Graignic-Philippe, R., Dayan, J., Chokron, S., Jacquet, A. Y., \& Tordjman, S. (2014). Effects of prenatal stress on fetal and child development: A critical literature review. Neuroscience and Biobehavioral Reviews, 43, 137-162. doi:10.1016/j.neubiorev.2014.03.022.

Groot, W. (2000). Adaptation and scale of reference bias in self-assessments of quality of life. Journal of Health Economics, 19(3), 403-420.

Gross, S. J., Mettelman, B. B., Dye, T. D., \& Slagle, T. A. (2001). Impact of family structure and stability on academic outcome in preterm children at 10 years of age. The Journal of Pediatrics, 138(2), 169-175. doi:10.1067/mpd.2001.111945.

Hack, M., Flannery, D. J., Schluchter, M., Cartar, L., Borawski, E., \& Klein, N. (2002). Outcomes in young adulthood for very-low-birth-weight infants. The New England Journal of Medicine, 346(3), 149-157. doi:10.1056/NEJMoa010856.

Hamilton, B. E., Martin, J. A., Osterman, M. J., Curtin, S. C., \& Matthews, T. J. (2015). Births: Final data for 2014. National Vital Statistics Reports, 64(12), 1-64. Retrieved from http://www.ncbi.nlm.nih.gov/ pubmed/26727629.

Hille, E. T., den Ouden, A. L., Bauer, L., van den Oudenrijn, C., Brand, R., \& Verloove-Vanhorick, S. P. (1994). School performance at nine years of age in very premature and very low birth weight infants: Perinatal risk factors and predictors at five years of age. Collaborative project on preterm and small for gestational age (POPS) infants in The Netherlands. The Journal of Pediatrics, 125(3), 426-434.

Hille, E. T., Weisglas-Kuperus, N., van Goudoever, J. B., Jacobusse, G. W., Ens-Dokkum, M. H., de Groot, L., et al. (2007). Functional outcomes and participation in young adulthood for very preterm and very low birth weight infants: The Dutch project on preterm and small for gestational age infants at 19 years of age. Pediatrics, 120(3), e587-e595. doi:10.1542/ peds.2006-2407.

Himmelmann, K., \& Uvebrant, P. (2014). The panorama of cerebral palsy in Sweden. XI. Changing patterns in the birth-year period 2003-2006. Acta Paediatrica, 103(6), 618-624. doi:10.1111/apa.12614.

Hintz, S. R., Kendrick, D. E., Vohr, B. R., Poole, W. K., \& Higgins, R. D. (2008). Community supports after surviving extremely low-birth-weight, extremely preterm birth: Special outpatient services in early childhood. Archives of Pediatrics \& Adolescent Medicine, 162(8), 748-755. doi:10.1001/ archpedi.162.8.748.

Hofman, P. L., Regan, F., Jackson, W. E., Jefferies, C., Knight, D. B., Robinson, E. M., et al. (2004). Premature birth and later insulin resistance. The New England Journal of Medicine, 351(21), 2179-2186. doi:10.1056/NEJMoa042275.

Hoirisch-Clapauch, S., Brenner, B., \& Nardi, A. E. (2015). Adverse obstetric and neonatal outcomes in women with mental disorders. Thrombosis Research, 135(Suppl 1), S60-S63. doi:10.1016/ s0049-3848(15)50446-5.

Holzmann, R., \& Jørgensen, S. (2001). Social risk management: A new conceptual framework for social protection, and beyond. International Tax and Public Finance, 8(4), 529-556. doi:10.102 3/A:1011247814590.

Howard, L. M., Piot, P., \& Stein, A. (2014). No health without perinatal mental health. The Lancet, 384(9956), 1723-1724. doi:10.1016/S0140-6736(14)62040-7.

Huston, A. C. (1991). Children in poverty : Child development and public policy. Cambridge, NY: Cambridge University Press.

Income, Poverty, and Health Insurance Coverage in the United States: 2005 (2006). In U. S. C. Bureau (Ed.).

Irving, R. J., Belton, N. R., Elton, R. A., \& Walker, B. R. (2000). Adult cardiovascular risk factors in premature babies. Lancet, 355(9221), 2135-2136. doi:10.1016/ s0140-6736(00)02384-9.

Jiang Y. E. M., \& Skinner C. (2015). Basic facts about low-income children: Children under 3 Years, 2013 (trans: D. o. H. P. Management). Columbia University: National Center for Children in Poverty.

Johnson, S., Hennessy, E., Smith, R., Trikic, R., Wolke, D., \& Marlow, N. (2009). Academic attainment and special educational needs in extremely preterm children at 11 years of age: The EPICure study. Archives of Disease in Childhood. Fetal and Neonatal Edition, 94(4), F283-F289. doi:10.1136/ adc.2008.152793. 
Johnson, S., Wolke, D., Hennessy, E., \& Marlow, N. (2011). Educational outcomes in extremely preterm children: Neuropsychological correlates and predictors of attainment. Developmental Neuropsychology, 36(1), 74-95. doi:10.1080/87565641.2011.540541.

Jones, K. M., Champion, P. R., \& Woodward, L. J. (2013). Social competence of preschool children born very preterm. Early Human Development, 89(10), 795802. doi:10.1016/j.earlhumdev.2013.06.008.

Joseph, R. M., O'Shea, T. M., Allred, E. N., Heeren, T., Hirtz, D., Paneth, N., Leviton, A., \& Kuban, K. C. (2016). Prevalence and associated features of autism spectrum disorder in extremely low gestational age newborns at age 10 years. Autism Research, 10(2), 224-232. doi:10.1002/aur.1644.

Kaijser, M., Bonamy, A. K., Akre, O., Cnattingius, S., Granath, F., Norman, M., et al. (2008). Perinatal risk factors for ischemic heart disease: Disentangling the roles of birth weight and preterm birth. Circulation, 117(3), 405-410. doi:10.1161/circulationaha.107.710715.

Kane, H. S., Dunkel Schetter, C., Glynn, L. M., Hobel, C. J., \& Sandman, C. A. (2014). Pregnancy anxiety and prenatal cortisol trajectories. Biological Psychology, 100, 13-19. doi:10.1016/j.biopsycho.2014.04.003.

Lang, C. T., \& Iams, J. D. (2009). Goals and strategies for prevention of preterm birth: An obstetric perspective. Pediatric Clinics of North America, 56(3), 537-563.

Lefebvre, F., Mazurier, E., \& Tessier, R. (2005). Cognitive and educational outcomes in early adulthood for infants weighing 1000 grams or less at birth. Acta Paediatrica, 94(6), 733-740. doi:10.1080/08035250510025987.

Litt, J. S., Gerry Taylor, H., Margevicius, S., Schluchter, M., Andreias, L., \& Hack, M. (2012). Academic achievement of adolescents born with extremely low birth weight. Acta Paediatrica, 101(12), 1240-1245. doi:10.1111/j.1651-2227.2012.02790.x.

MacCabe, J. H., Martinsson, L., Lichtenstein, P., Nilsson, E., Cnattingius, S., Murray, R. M., et al. (2007). Adverse pregnancy outcomes in mothers with affective psychosis. Bipolar Disorders, 9(3), 305-309. doi:10.1111/j.1399-5618.2007.00382.x.

Marciniak, B., Patro-Malysza, J., PoniedzialekCzajkowska, E., Kimber-Trojnar, Z., LeszczynskaGorzelak, B., \& Oleszczuk, J. (2011). Glucocorticoids in pregnancy. Current Pharmaceutical Biotechnology, 12(5), 750-757.

McLean, M., Bisits, A., Davies, J., Woods, R., Lowry, P., \& Smith, R. (1995). A placental clock controlling the length of human pregnancy. Nature Medicine, 1(5), 460-463.

Morse, S. B., Zheng, H., Tang, Y., \& Roth, J. (2009). Early school-age outcomes of late preterm infants. Pediatrics, 123(4), e622-e629. doi:10.1542/peds.2008-1405.

Moster, D., Lie, R. T., \& Markestad, T. (2008). Long-term medical and social consequences of preterm birth. The
New England Journal of Medicine, 359(3), 262-273. doi:10.1056/NEJMoa0706475.

Msall, M. E. (2012). Academic achievement after extreme prematurity: Optimizing outcomes for vulnerable children in times of uncertainty. Acta Paediatrica, 101(12), 1196-1197. doi:10.1111/apa.12038.

Msall, M. E., Phelps, D. L., DiGaudio, K. M., Dobson, V., Tung, B., McClead, R. E., et al. (2000). Severity of neonatal retinopathy of prematurity is predictive of neurodevelopmental functional outcome at age 5.5 years. Behalf of the Cryotherapy for retinopathy of prematurity cooperative group. Pediatrics, 106(5), 998-1005.

Msall, M. E., Phelps, D. L., Hardy, R. J., Dobson, V., Quinn, G. E., Summers, C. G., et al. (2004). Educational and social competencies at 8 years in children with threshold retinopathy of prematurity in the CRYO-ROP multicenter study. Pediatrics, 113(4), 790-799.

O'Connor, T. G., Monk, C., \& Fitelson, E. M. (2014). Practitioner review: Maternal mood in pregnancy and child development--implications for child psychology and psychiatry. Journal of Child Psychology and Psychiatry, 55(2), 99-111. doi:10.1111/jcpp.12153.

van Oppenraaij, R. H., Jauniaux, E., Christiansen, O. B., Horcajadas, J. A., Farquharson, R. G., \& Exalto, N. (2009). Predicting adverse obstetric outcome after early pregnancy events and complications: A review. Human Reproduction Update, 15(4), 409-421. doi:10.1093/humupd/dmp009.

Patrianakos-Hoobler, A. I., Msall, M. E., Marks, J. D., Huo, D., \& Schreiber, M. D. (2009). Risk factors affecting school readiness in premature infants with respiratory distress syndrome. Pediatrics, 124(1), 258-267. doi:10.1542/peds.2008-1771.

Pinto-Martin, J. A., Levy, S. E., Feldman, J. F., Lorenz, J. M., Paneth, N., \& Whitaker, A. H. (2011). Prevalence of autism spectrum disorder in adolescents born weighing <2000 grams. Pediatrics, 128(5), 883891. doi:10.1542/peds.2010-2846.

Poehlmann, J., Hane, A., Burnson, C., Maleck, S., Hamburger, E., \& Shah, P. E. (2012). Preterm infants who are prone to distress: Differential effects of parenting on 36-month behavioral and cognitive outcomes. Journal of Child Psychology and Psychiatry, 53(10), 1018-1025. doi:10.1111/j.1469-7610.2012.02564.x.

Preterm Birth: Causes, Consequences, and Prevention (2007). In R. E. Behrman, \& A. S. Butler (Eds.). Washington, DC: Committee on Understanding Premature Birth and Assuring Healthy Outcomes, Institute of Medicine of the Academies.

Provencal, N., \& Binder, E. B. (2015). The effects of early life stress on the epigenome: From the womb to adulthood and even before. Experimental Neurology, 268, 10-20. doi:10.1016/j.expneurol.2014.09.001. 
Requejo, J., Merialdi, M., Althabe, F., Keller, M., Katz, J., \& Menon, R. (2013). Born too soon: Care during pregnancy and childbirth to reduce preterm deliveries and improve health outcomes of the preterm baby. Reproductive Health, 10(Suppl 1), S4. doi:10.1186/1742-4755-10-s1-s4.

Rini, C. K., Dunkel-Schetter, C., Wadhwa, P. D., \& Sandman, C. A. (1999). Psychological adaptation and birth outcomes: The role of personal resources, stress, and sociocultural context in pregnancy. Health Psychology, 18(4), 333-345.

Rosenberg, S. A., Zhang, D., \& Robinson, C. C. (2008). Prevalence of developmental delays and participation in early intervention services for young children. Pediatrics, 121(6), e1503-e1509. doi:10.1542/ peds.2007-1680.

Rubens, C. E., Sadovsky, Y., Muglia, L., Gravett, M. G., Lackritz, E., \& Gravett, C. (2014). Prevention of preterm birth: Harnessing science to address the global epidemic. Science Translational Medicine, 6(262), 262sr265. doi:10.1126/scitranslmed.3009871.

Sable, M. R., \& Wilkinson, D. S. (2000). Impact of perceived stress, major life events and pregnancy attitudes on low birth weight. Family Planning Perspectives, 32(6), 288-294.

Saigal, S., \& Doyle, L. W. (2008). An overview of mortality and sequelae of preterm birth from infancy to adulthood. Lancet, 371(9608), 261-269. doi:10.1016/ s0140-6736(08)60136-1.

Saigal, S., Pinelli, J., Hoult, L., Kim, M. M., \& Boyle, M. (2003). Psychopathology and social competencies of adolescents who were extremely low birth weight. Pediatrics, 111(5 Pt 1), 969-975.

Shah, P. E., Robbins, N., Coelho, R. B., \& Poehlmann, J. (2013). The paradox of prematurity: The behavioral vulnerability of late preterm infants and the cognitive susceptibility of very preterm infants at 36 months post-term. Infant Behavior \& Development, 36(1), 50-62. doi:10.1016/j.infbeh.2012.11.003.

Simms, V., Gilmore, C., Cragg, L., Clayton, S., Marlow, N., \& Johnson, S. (2015). Nature and origins of mathematics difficulties in very preterm children: A different etiology than developmental dyscalculia. Pediatric Research, 77(2), 389-395. doi:10.1038/pr.2014.184.

Smith, C. J., \& Ryckman, K. K. (2015). Epigenetic and developmental influences on the risk of obesity, diabetes, and metabolic syndrome. Diabetes Metab Syndr Obes, 8, 295-302. doi:10.2147/dmso.s61296.

Stein, A., Pearson, R. M., Goodman, S. H., Rapa, E., Rahman, A., McCallum, M., et al. (2014). Effects of perinatal mental disorders on the fetus and child. Lancet, 384(9956), 1800-1819. doi:10.1016/ s0140-6736(14)61277-0.

Stephens, B. E., \& Vohr, B. R. (2009). Neurodevelopmental outcome of the premature infant. Pediatric Clinics of North America, 56(3), 631-646., Table of Contents. doi:10.1016/j.pcl.2009.03.005.
The March of Dimes data book for policy makers: Maternal, infant, and child health in the United States (2012). Washington, DC: March of Dimes.

Torche, F., \& Kleinhaus, K. (2012). Prenatal stress, gestational age and secondary sex ratio: The sex-specific effects of exposure to a natural disaster in early pregnancy. Human Reproduction, 27(2), 558-567. doi:10.1093/humrep/der390.

Treyvaud, K., Ure, A., Doyle, L. W., Lee, K. J., Rogers, C. E., Kidokoro, H., et al. (2013). Psychiatric outcomes at age seven for very preterm children: Rates and predictors. Journal of Child Psychology and Psychiatry, 54(7), 772-779. doi:10.1111/jcpp.12040.

Vohr, B. (2013). Long-term outcomes of moderately preterm, late preterm, and early term infants. Clinics in Perinatology, 40(4), 739-751. doi:10.1016/j. clp.2013.07.006.

Vohr, B. R., \& Msall, M. E. (1997). Neuropsychological and functional outcomes of very low birth weight infants. Seminars in Perinatology, 21(3), 202-220.

Wadhwa, P. D., Dunkel-Schetter, C., Chicz-DeMet, A., Porto, M., \& Sandman, C. A. (1996). Prenatal psychosocial factors and the neuroendocrine axis in human pregnancy. Psychosomatic Medicine, 58(5), 432-446.

Wainstock, T., Anteby, E. Y., Glasser, S., Lerner-Geva, L., \& Shoham-Vardi, I. (2014). Exposure to lifethreatening stressful situations and the risk of preterm birth and low birth weight. International Journal of Gynaecology and Obstetrics, 125(1), 28-32. doi:10.1016/j.ijgo.2013.09.035.

Weiss, E. L., Msall, M.E., \& Muhammad, C. (2007). Barriers to receipt of early intervention. Passages. doi:E-PAS2007:616311.10.

Weitzman, M., Byrd, R. S., Aligne, C. A., \& Moss, M. (2002). The effects of tobacco exposure on children's behavioral and cognitive functioning: Implications for clinical and public health policy and future research. Neurotoxicology and Teratology, 24(3), 397-406.

Wijesiriwardana, A., Bhattacharya, S., Shetty, A., Smith, N., \& Bhattacharya, S. (2006). Obstetric outcome in women with threatened miscarriage in the first trimester. Obstetrics and Gynecology, 107(3), 557-562. doi:10.1097/01.AOG.0000199952.82151.de.

Williams, M. A., Mittendorf, R., Lieberman, E., \& Monson, R. R. (1991). Adverse infant outcomes associated with first-trimester vaginal bleeding. Obstetrics and Gynecology, 78(1), 14-18.

Williams, J.,Lee, K. J., \&Anderson, P.J. (2010). Prevalence of motor-skill impairment in preterm children who do not develop cerebral palsy: A systematic review. Developmental Medicine and Child Neurology, 52(3), 232-237. doi:10.1111/j.1469-8749.2009.03544.x.

Winchester, S. B., Sullivan, M. C., Roberts, M. B., \& Granger, D. A. (2016). Prematurity, birth weight, and socioeconomic status are linked to atypical diurnal hypothalamic-pituitary-adrenal Axis activity in young adults. Research in Nursing \& Health, 39(1), 15-29. 
Wolke, D., Strauss, V. Y., Johnson, S., Gilmore, C., Marlow, N., \& Jaekel, J. (2015). Universal gestational age effects on cognitive and basic mathematic processing: 2 cohorts in 2 countries. J Pediatr, 166(6), 1410-1416. doi:10.1016/j.jpeds.2015.02.065.

World Health Organization. (2007). ICF-CY, international classification of functioning, disability, and health: Children \& Youth version. Geneva: World Health Organization.

Yonkers, K. A., Smith, M. V., Forray, A., Epperson, C. N., Costello, D., Lin, H., et al. (2014). Pregnant women with posttraumatic stress disorder and risk of preterm birth. JAMA Psychiatry, 71(8), 897-904. doi:10.1001/ jamapsychiatry.2014.558.

Open Access This chapter is licensed under the terms of the Creative Commons Attribution 4.0 International License (http://creativecommons.org/licenses/by/4.0/), which permits use, sharing, adaptation, distribution and reproduction in any medium or format, as long as you give appropriate credit to the original author(s) and the source, provide a link to the Creative Commons license and indicate if changes were made.

The images or other third party material in this chapter are included in the chapter's Creative Commons license, unless indicated otherwise in a credit line to the material. If material is not included in the chapter's Creative Commons license and your intended use is not permitted by statutory regulation or exceeds the permitted use, you will need to obtain permission directly from the copyright holder. 